\title{
Preactivation-based chemoselective glycosylations: A powerful strategy for oligosaccharide assembly
}

\author{
Weizhun Yang ${ }^{\ddagger 1}$, Bo Yang ${ }^{\ddagger 1}$, Sherif Ramadan ${ }^{1,2}$ and Xuefei Huang ${ }^{* 1,3}$
}

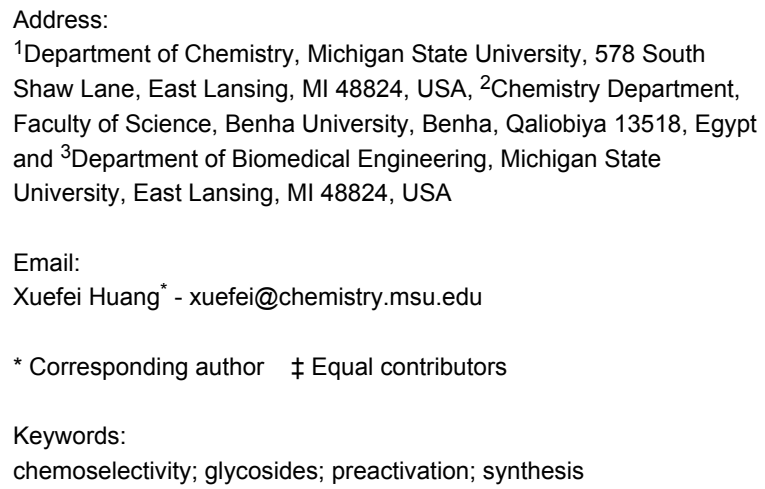

Beilstein J. Org. Chem. 2017, 13, 2094-2114. doi:10.3762/bjoc. 13.207

Received: 01 May 2017

Accepted: 14 September 2017

Published: 09 October 2017

This article is part of the Thematic Series "The glycosciences".

Guest Editor: A. Hoffmann-Röder

(C) 2017 Yang et al.; licensee Beilstein-Institut. License and terms: see end of document.

\begin{abstract}
Most glycosylation reactions are performed by mixing the glycosyl donor and acceptor together followed by the addition of a promoter. While many oligosaccharides have been synthesized successfully using this premixed strategy, extensive protective group manipulation and aglycon adjustment often need to be performed on oligosaccharide intermediates, which lower the overall synthetic efficiency. Preactivation-based glycosylation refers to strategies where the glycosyl donor is activated by a promoter in the absence of an acceptor. The subsequent acceptor addition then leads to the formation of the glycoside product. As donor activation and glycosylation are carried out in two distinct steps, unique chemoselectivities can be obtained. Successful glycosylation can be performed independent of anomeric reactivities of the building blocks. In addition, one-pot protocols have been developed that have enabled multiple-step glycosylations in the same reaction flask without the need for intermediate purification. Complex glycans containing both 1,2-cis and 1,2-trans linkages, branched oligosaccharides, uronic acids, sialic acids, modifications such as sulfate esters and deoxy glycosides have been successfully synthesized. The preactivation-based chemoselective glycosylation is a powerful strategy for oligosaccharide assembly complementing the more traditional premixed method.
\end{abstract}

\section{Review}

\section{Introduction}

Carbohydrates are widely present in nature and many of them are involved in important physiological and pathological events, such as anticoagulation, inflammation and pathogen infection $[1,2]$. In order to explore their biological functions, oligosaccha- rides with high purity are needed [3]. However, this is hampered by the limited availability of complex glycans from nature. Thus, chemical synthesis is a powerful approach to provide much needed samples to enable biological studies [4]. 
Traditional carbohydrate synthesis is commonly carried out from the reducing end to the non-reducing end with a glycosyl donor premixed with an acceptor. Upon the addition of a promoter to the reaction mixture, the donor is activated to glycosylate the acceptor yielding a disaccharide, which is subsequently deprotected to expose a free hydroxy group (Scheme 1a). The newly generated acceptor can be coupled with another donor and this process is repeated until the desired oligosaccharide structure is assembled. Although many oligosaccharides have been successfully produced through this approach, the traditional oligosaccharide synthesis requires multiple synthetic manipulations on oligosaccharide intermediates, which lowers the overall synthetic efficiency.

To expedite the oligosaccharide assembly process, many innovative strategies have been developed [5], such as active-latent activation [6-8], orthogonal glycosylation $[9,10]$, reactivitybased armed-disarmed glycosylation [11-14], fluorine-supported glycosylation $[15,16]$ and automated solid-phase synthesis [17]. All of these methods use the donor/acceptor premixed approach and preferential activation of the donor is achieved by the higher anomeric reactivity of the donor towards the promoter compared to the acceptor. In comparison, the preactivation-based iterative glycosylation is unique, where a glycosyl donor is preactivated in the absence of an acceptor to produce a reactive intermediate (Scheme 1b) [18-21]. Upon complete donor activation, the acceptor is added to the reaction mixture, which nucleophilically attacks the intermediate forming the desired glycosidic product [22-24].
With the preactivation protocol, the donor activation and acceptor glycosylation occur in two distinctive steps. As a result, a unique chemoselectivity can be achieved with preactivation. Glycosyl donors and acceptors with the same aglycon leaving group can be used enabling an iterative glycosylation, simplifying the overall synthetic design.

For a preactivation based glycosylation reaction to be successful the intermediate formed upon preactivation must be stable prior to the addition of the acceptor and yet reactive enough to quickly react with the acceptor during the glycosylation step without the need for another exogenous promoter or separation of the intermediate. Various types of glycosyl building blocks and promoter systems have been developed for preactivation. This review will be divided according to the type of glycosyl donors that can undergo a preactivation-based chemoselective glycosylation with an emphasis on thioglycosides due to their wide applicability.

\section{Preactivation of glycosyl sulfoxides: early success of preactivation}

One of the earliest preactivation-based glycosylation reactions utilized glycosyl sulfoxide donors for glycosylation of unreactive substrates such as steroid derivative $\mathbf{2}$ by the Kahne group [25]. The axial C-7 hydroxy group in $\mathbf{2}$ is sterically hindered due to unfavorable 1,3-diaxial interactions. The traditional premixed glycosylation gave only low yields $(<30 \%)$ of the products [26]. In contrast, when glycosyl sulfoxide donor 1 was preactivated with $\mathrm{Tf}_{2} \mathrm{O}$ at $-78{ }^{\circ} \mathrm{C}$, followed by the addition of

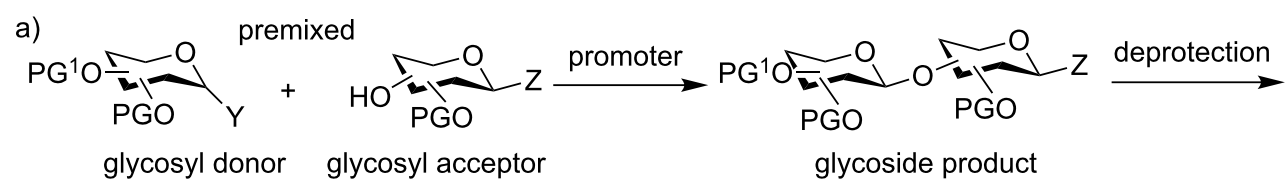

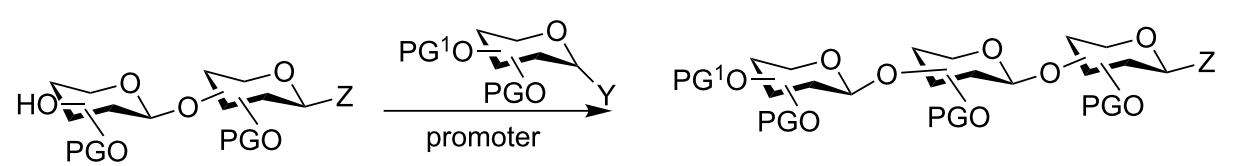

b)
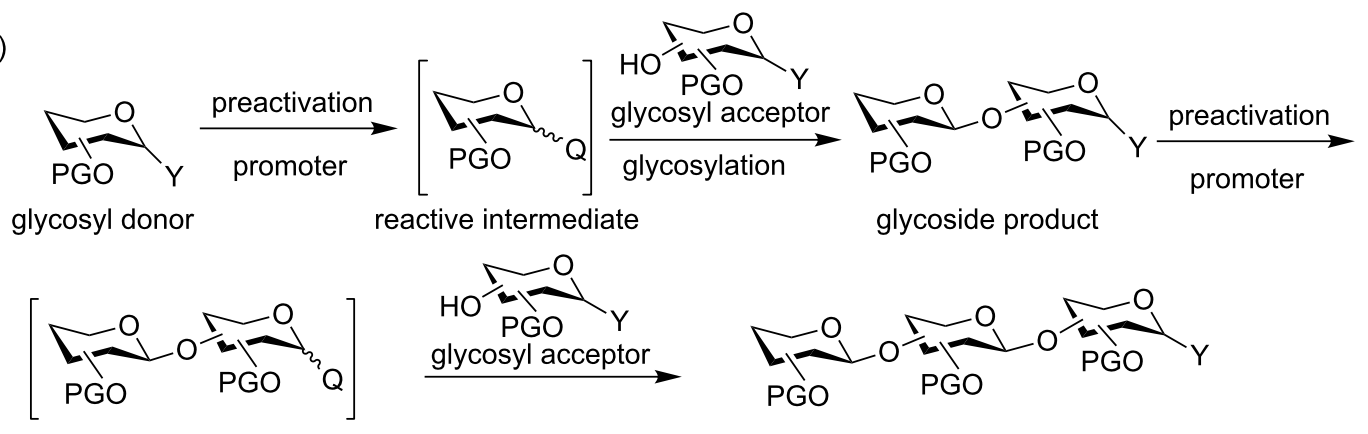

Scheme 1: a) Traditional glycosylation typically employs the premixed approach with both the donor and the acceptor mixed together, before the promoter is added; b) the preactivation based glycosylation strategy activates the glycosyl donor in the absence of the acceptor, which temporally separates the donor activation step from acceptor glycosylation. 
sterol 2 and 2,6-di-tert-butyl-4-methylpyridine (DTBMP) as an acid scavenger, the desired compound $\mathbf{3}$ was obtained in an excellent $86 \%$ yield (Scheme 2). While this method has not been applied to glycosyl sulfoxide as the acceptor for iterative glycosylation, this early example demonstrated the power of preactivation. Subsequently, a wide range of glycosyl donors have been explored.

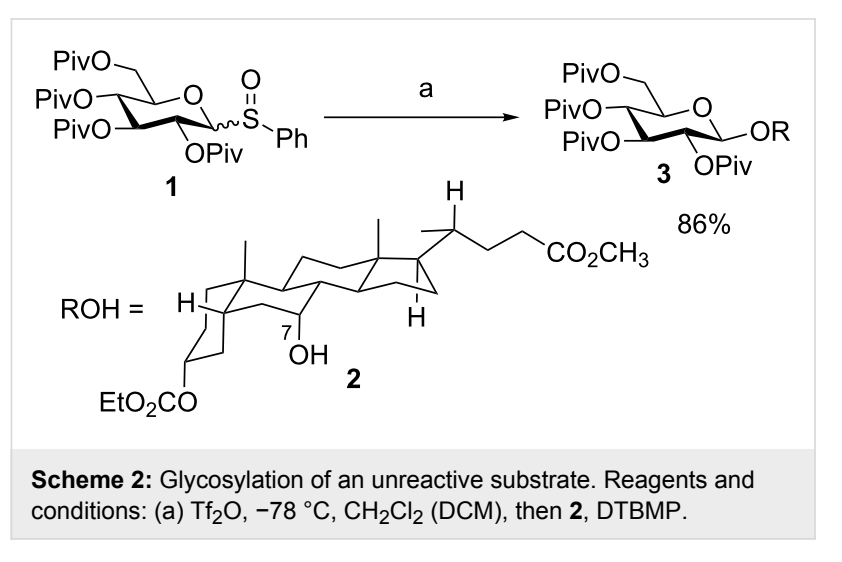

\section{$\beta$-Glycosyl bromide-mediated iterative gycosylation of selenoglycosides}

Yoshida and co-workers developed a preactivation-based glycosylation approach using selenoglycosides via the intermediacy of $\beta$-glycosyl bromides (Scheme 3) [27,28]. Upon the addition of 0.5 equiv of bromine, half of the selenoglycoside donor 4 would be activated to presumably form glycosyl bromide $\mathbf{5}$ accompanied by the generation of $\mathrm{PhSeBr}$. $\mathrm{PhSeBr}$ could react with the remaining donor $\mathbf{4}$ for quantitative activation of $\mathbf{4}$. The addition of the acceptor to the reaction mixture upon donor preactivation afforded orthoester $\mathbf{6}$. The orthoester $\mathbf{6}$ was rearranged in situ with trimethylsilyl trifluoromethanesulfonate
(TMSOTf) to disaccharide 7, which could be subjected to bromine-promoted glycosylation for further chain elongation. As an example, preactivation of a monosaccharide $\mathbf{8}$ with bromine was followed by the addition of a bifunctional disaccharide building block 10 and subsequent TMSOTf-promoted orthoester rearrangement, producing trisaccharide selenoglycoside 11 in 90\% yield (Scheme 4). Following the same reaction protocol trisaccharide $\mathbf{1 1}$ and glycosylated acceptor $\mathbf{9}$ lead to tetrasaccharide 12, which was further extended to heptasaccharide 13. This method has also been applied to generate a library of phytoalexin elicitor-active oligoglucosides [28].

A limitation of this glycosyl bromide-mediated selenoglycoside iterative glycosylation is that it is restricted to the formation of 1,2-trans-glycosyl linkages. Furthermore, an additional isomerization step is needed to transform the orthoester to the desired glycoside.

\section{Preactivation-based iterative glycosylation of 2-pyridyl glycosides}

$O$-Unprotected 2-pyridyl glycosyl donors have been utilized in oligosaccharide synthesis [29]. The Ye group reported a preactivation protocol using protected 2-pyridyl donors [30]. The preactivation of 2-pyridyl glycoside $\mathbf{1 4}$ was performed using $\mathrm{Tf}_{2} \mathrm{O}$ as the promoter, which was followed by the addition of acceptor 15 generating disaccharide $\mathbf{1 6}$ in $96 \%$ yield (Scheme 5a). The acceptor could also bear a 2-pyridyl aglycon such as acceptor 18. The preactivation-based glycosylation of donor $\mathbf{1 7}$ with acceptor $\mathbf{1 8}$ led to a disaccharide intermediate, which was then subjected to another round of $\mathrm{Tf}_{2} \mathrm{O}$-mediated glycosylation leading to trisaccharide $\mathbf{2 0}$ in one pot (Scheme 5b). As compounds $\mathbf{1 6}$ and $\mathbf{2 0}$ have relatively simple structures, the scope of this 2-pyridyl glycosylation method will

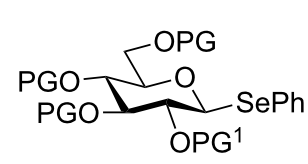

4

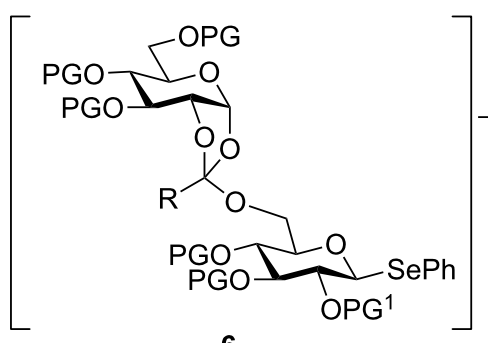

6
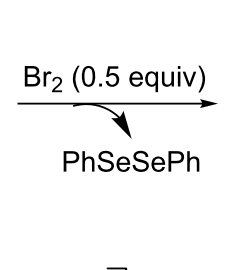

$P G^{1}=B z$ or $A c$

$\mathrm{R}=\mathrm{Ph}$ or $\mathrm{Me}$

$P G=$ protecting group

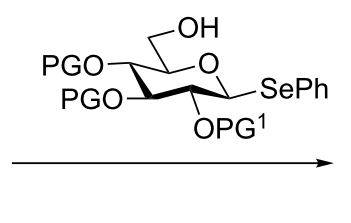

5 cat. TMSOTf
7 


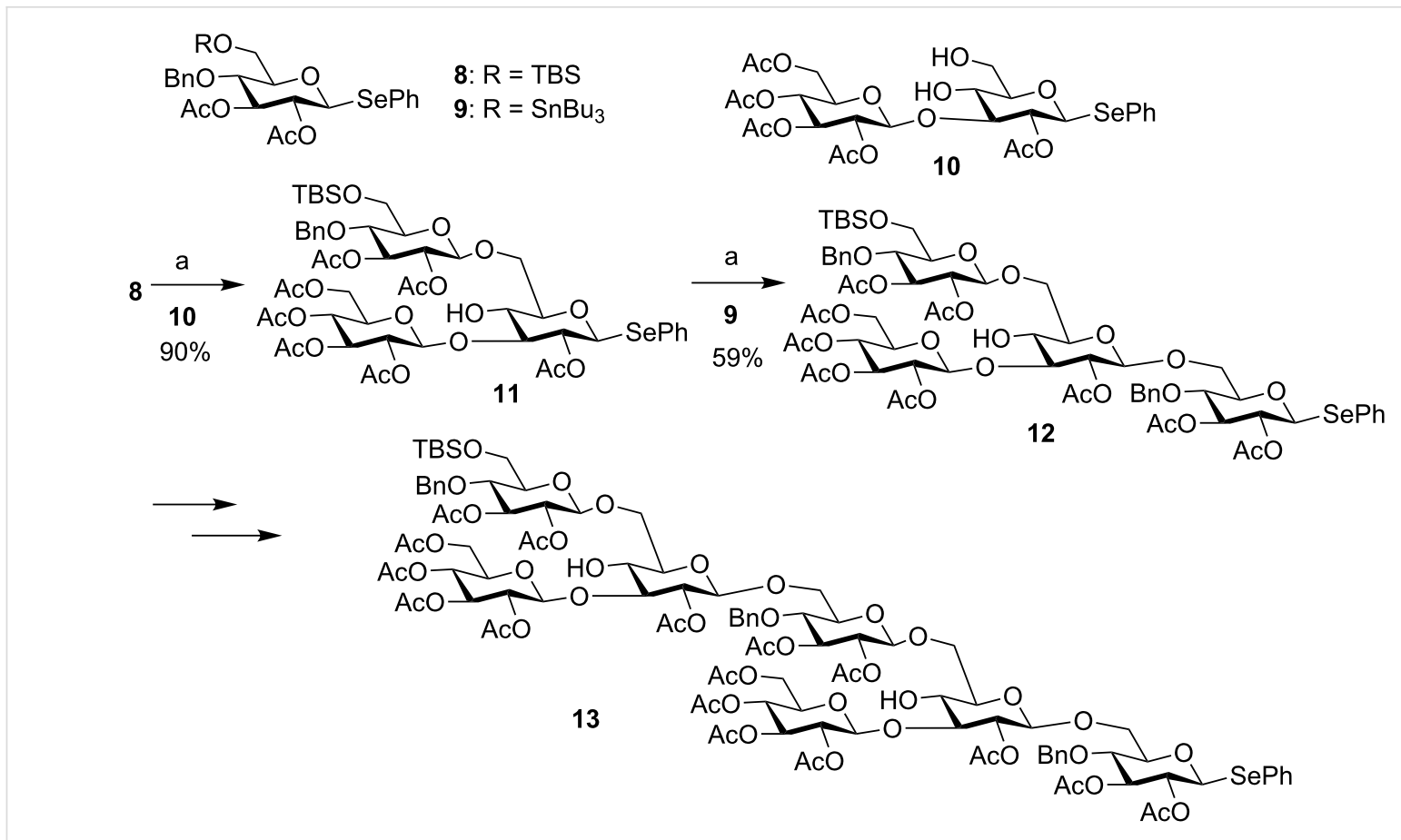

Scheme 4: Glycosyl bromide-mediated selenoglycosyl donor-based iterative glycosylation. Reagents and conditions: (a) $\mathrm{Br}_{2},\left(0.5\right.$ equiv), $0{ }^{\circ} \mathrm{C}$, $\mathrm{CH}_{2} \mathrm{Cl}_{2}$; then 10 or 9 , rt; then TMSOTf ( 0.1 equiv), $0{ }^{\circ} \mathrm{C}$.

a)<smiles>CC(=O)OCC1OC(=O)OCC(Oc2ccccn2)C1OC(C)=O</smiles>

14

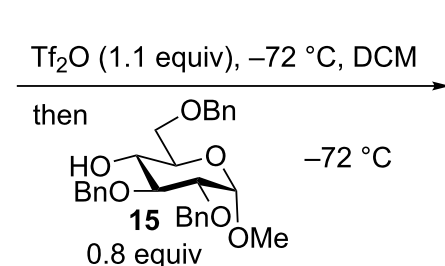

0.8 equiv

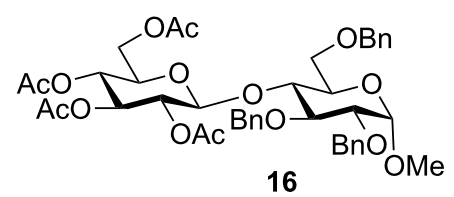

$96 \%$

b)

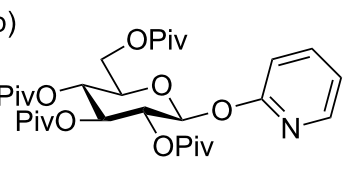

17

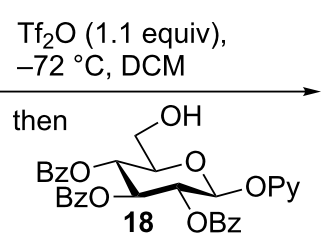

0.8 equiv, $-72^{\circ} \mathrm{C}$ to $\mathrm{rt}$

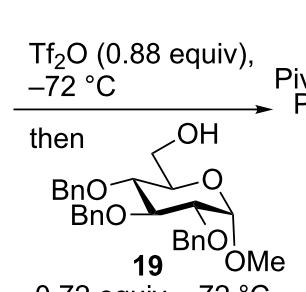

0.72 equiv, $-72^{\circ} \mathrm{C}$

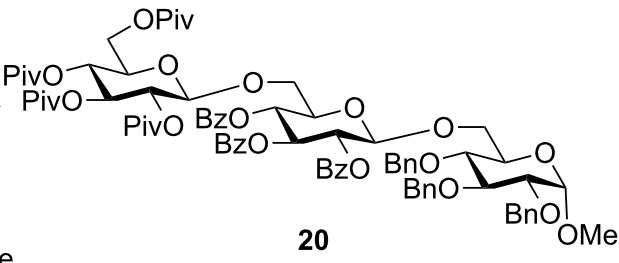

$84 \%$

Scheme 5: Preactivation-based glycosylation using 2-pyridyl glycosyl donors.

need to be established in the total synthesis of more complex oligosaccharides.

\section{Chemoselective dehydrative glycosylation with glycosyl hemiacetals}

Most glycosylation reactions require a functionalization of the anomeric position of a glycosyl donor followed by the reaction with a promoter to induce the irreversible transfer of the donor to an acceptor [31-35]. The displacement of the anomeric hydroxy group of a glycosyl hemiacetal by an acceptor for dehydrative glycosylation is an interesting alternative as glycosyl hemiacetals are often undesired side products in glycosylation reactions due to the competitive reaction with trace amounts of water present in the reaction mixture. The Gin group established a preactivation glycosylation procedure using glycosyl hemiacetals [36]. As an example, the hemiacetal donor 21 was preactivated with $\mathrm{Tf}_{2} \mathrm{O}$ and diphenyl sulfoxide $\left(\mathrm{Ph}_{2} \mathrm{SO}\right)$ at $-40{ }^{\circ} \mathrm{C}$. This was followed by the addition of the acceptor isopropyl alcohol, affording glycoside 22 in $86 \%$ yield ( $\alpha: \beta=$ $27: 73$, Scheme 6 ). This glycosylation strategy can be applied to 


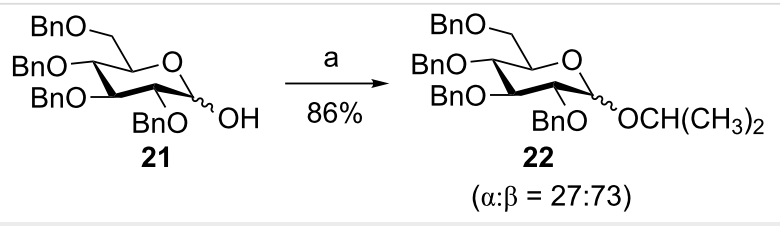

Scheme 6: Chemoselective dehydrative glycosylation. Reagents and conditions: (a) $\mathrm{Ph}_{2} \mathrm{SO}, \mathrm{Tf}_{2} \mathrm{O}$, 2-chloropyridine, then $\left(\mathrm{CH}_{3}\right)_{2} \mathrm{CHOH}$, $-40^{\circ} \mathrm{C}$.

a variety of glycosyl acceptors, including oxygen, sulfur, carbon and nitrogen nucleophiles (Figure 1) [36]. Even the unreactive $N$-(trimethylsilyl)trimethylacetamide could be efficiently glycosylated to afford the corresponding glycosyl amide $\mathbf{2 6}$.
Two possible reaction pathways have been proposed for this dehydrative glycosylation (Scheme 7) [37]. Upon mixing diphenyl sulfoxide and triflic anhydride, diphenyl sulfide bis(triflate) (27) is formed in situ (Scheme 7a). In pathway 1, hemiacetal 28 could attack the sulfonium center of diphenyl sulfide bis(triflate) (27) to give the glycosyl oxosulfonium intermediate 29, which subsequently glycosylated the acceptor to yield the product 30 (Scheme 7b). Alternatively, in pathway 2, hemiacetal $\mathbf{2 8}$ could attack the sulfonyl center of diphenyl sulfide bis(triflate) (27) to give the glycosyl triflate intermediate 31, followed by glycosylation to give $\mathbf{3 0}$ (Scheme 7c). To distinguish between these two possibilities, an ${ }^{18} \mathrm{O}$-labeling study was carried out by subjecting ${ }^{18} \mathrm{O}$-labeled hemiacetal 28

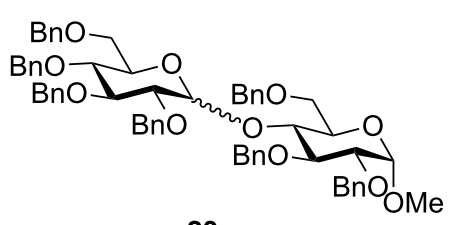

23a

$85 \%(\alpha: \beta=60: 40)$

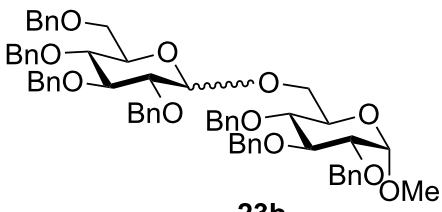

23b

$85 \%(\alpha: \beta=24: 76)$

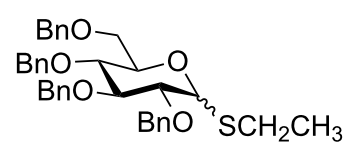

24

$84 \%(\alpha: \beta=83: 17)$

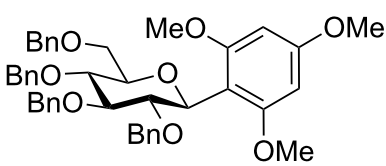

25

$81 \%(\beta)$

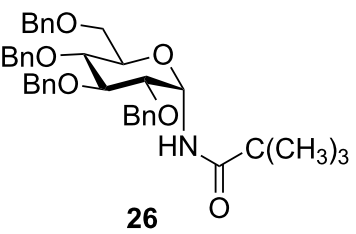

$89 \%(\alpha)$

Figure 1: Representative structures of products formed by the preactivation-based dehydrative glycosylation of glycosyl hemiacetal
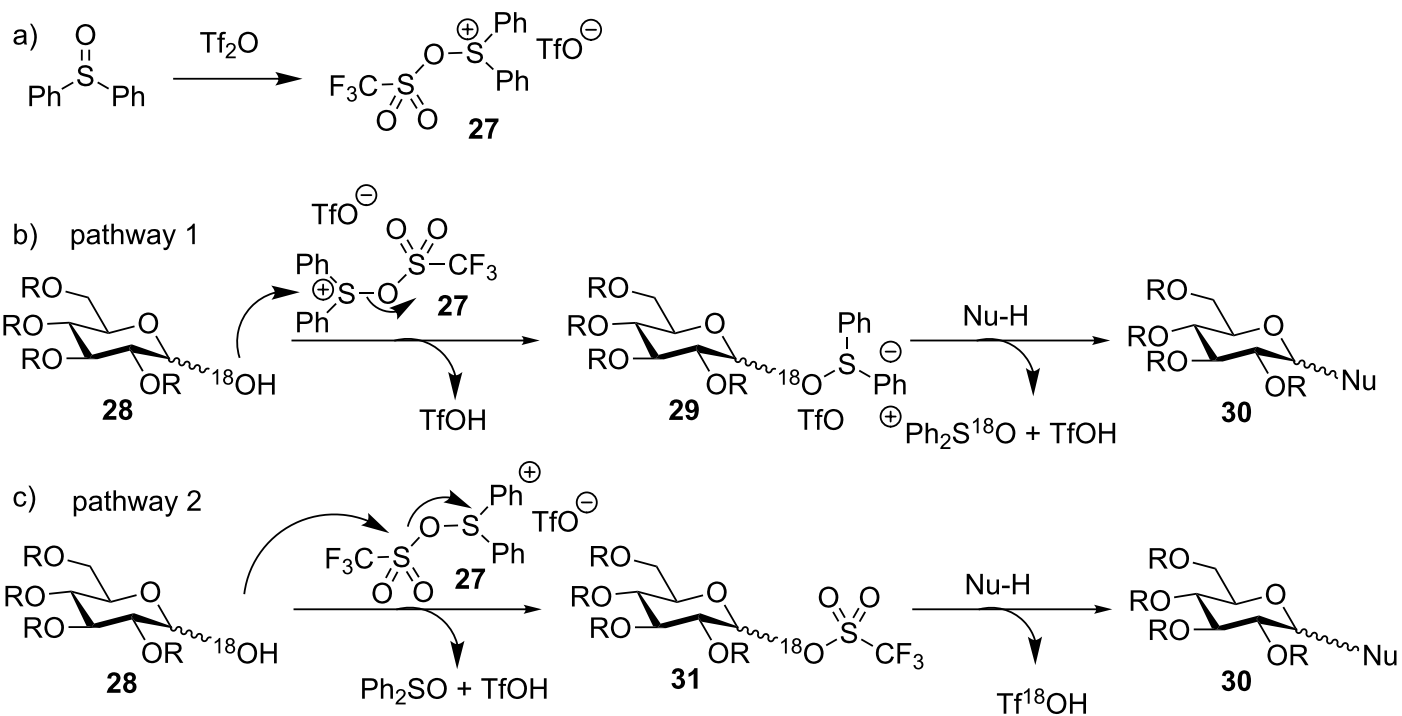
to the glycosylation conditions. Indeed, ${ }^{18} \mathrm{O}$-labeled diphenyl sulfoxide was detected in the reaction mixture as the main ${ }^{18} \mathrm{O}$-labeled compound, which suggested pathway 1 was the major reaction mechanism.

The hemiacetal donor can be utilized in iterative glycosylation (Scheme 8) [21]. Donor 32 was preactivated by $\mathrm{Ph}_{2} \mathrm{SO}$ and $\mathrm{Tf}_{2} \mathrm{O}$, followed by the addition of glycosyl hemiacetal $\mathbf{3 3}$ with one of its hydroxy groups free available as the acceptor producing disaccharide 34 . The regioselectivity is presumably due to the higher nucleophilicity of the alkyl hydroxy group than that of the hemiacetal hydroxy group. This process can be repeated for chain elongation without the need for any protective group manipulation or aglycon adjustment. Using this method, the 1,4- $\alpha$-linked tetrasaccharide 37 was prepared in good overall yield.

Inspired by Gin's work, van der Marvel and co-workers developed a sequential glycosylation strategy by combining hemiacetal and thioglycosyl building blocks as illustrated in Scheme 9 [38]. The hemiacetal donor $\mathbf{3 8}$ was preactivated with
$\mathrm{Ph}_{2} \mathrm{SO}$ and $\mathrm{Tf}_{2} \mathrm{O}$, and reacted with a bifunctional thioglycosyl acceptor 39 to form disaccharide 40. Interestingly, thioglycoside 40 could also be activated by $\mathrm{Ph}_{2} \mathrm{SO} / \mathrm{Tf}_{2} \mathrm{O}$. The subsequent addition of acceptor $\mathbf{4 1}$ to the reaction mixture furnished trisaccharide 42. This approach was applied to the synthesis of hyaluronic acid (HA) oligomers [39]. The sequential reaction of building blocks 43,44 and 46 led to HA trisaccharide 47 (Scheme 10). The modest overall yield of $26 \%$ for the two glycosylation reactions was attributed to the formation of orthoester and oxazolidine side products due to the basic reaction conditions, which were needed to neutralize the acid formed during glycosylation and to avoid the cleavage of the acid-labile benzylidene protective group.

The van der Marel group further applied their strategy to the synthesis of heparin (HP) and heparan sulfate (HS), which are more complex members of the glycosaminoglycan family [40]. A pentasaccharide 48 was chosen as the synthetic target (Figure 2). A major challenge of HP and HS synthesis lies in the coupling of an azido glucoside with a uronic acid in an $\alpha$-selective fashion. A variety of azido hemiacetal glucoside
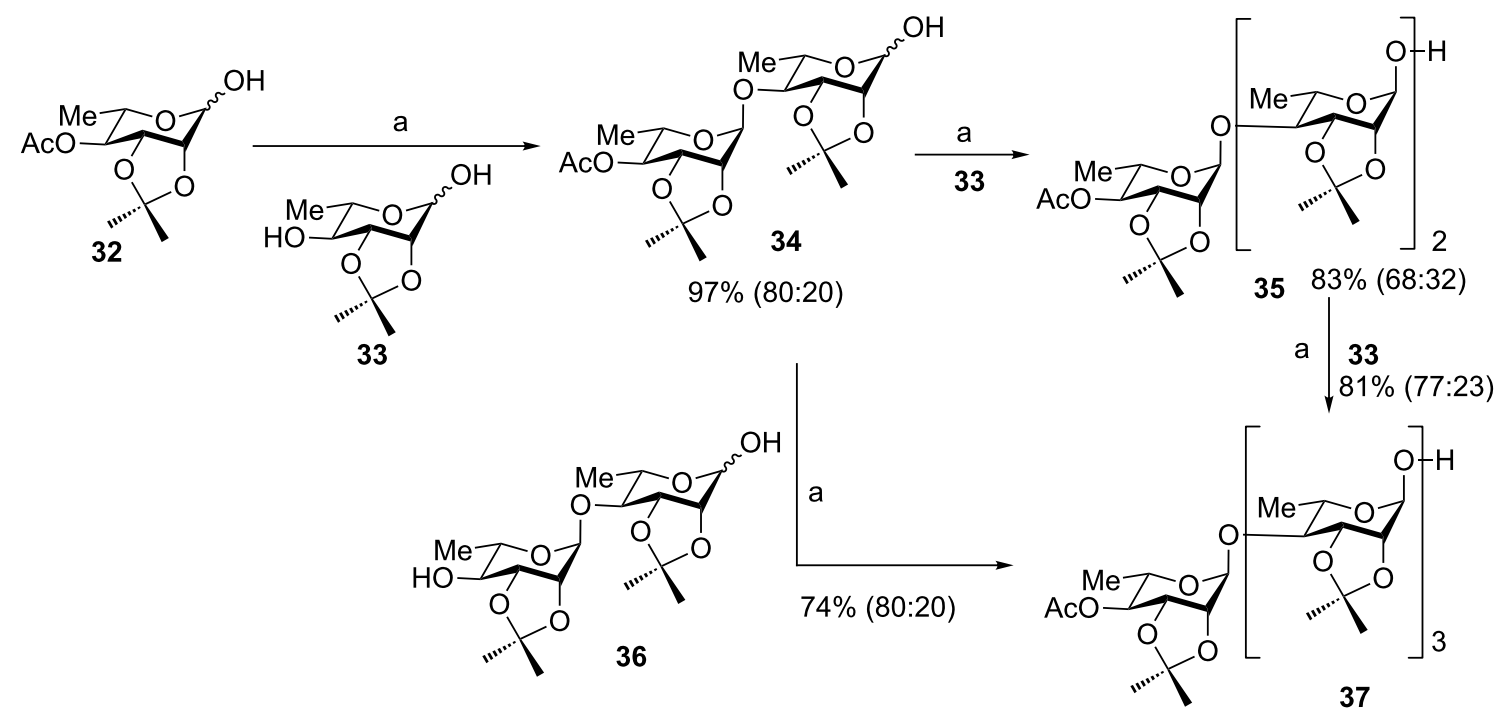

Scheme 8: Chemoselective iterative dehydrative glycosylation. Reagents and conditions: (a) $\mathrm{Ph}_{2} \mathrm{SO}, \mathrm{Tf}_{2} \mathrm{O}, 2,4,6$-tri-tert-butylpyrimidine (TTBP), $-78^{\circ} \mathrm{C}$ to $-40{ }^{\circ} \mathrm{C}$; then acceptor.

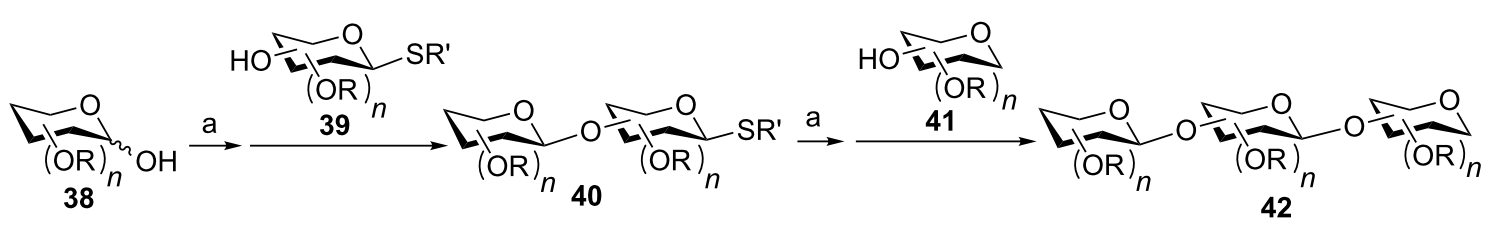




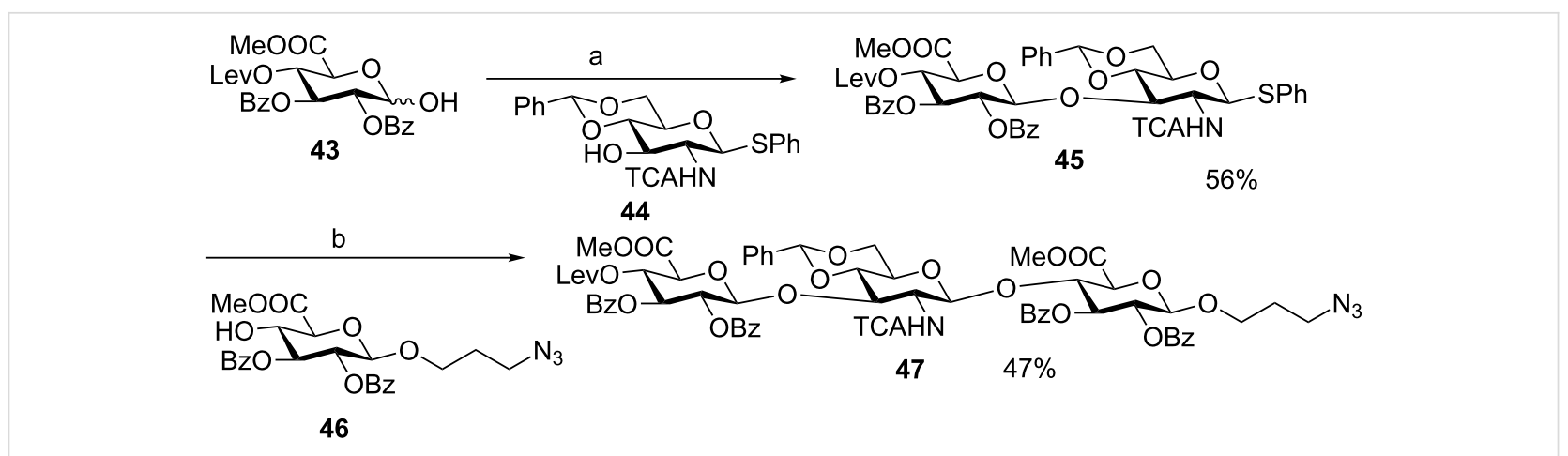

Scheme 10: Chemical synthesis of a hyaluronic acid (HA) trimer 47. Reagents and conditions: (a) $\mathrm{Ph}_{2} \mathrm{SO}, \mathrm{TTBP} \mathrm{CH}_{2} \mathrm{Cl}_{2},-60{ }^{\circ} \mathrm{C}$, then $\mathrm{Tf}_{2} \mathrm{O}, 44$, $-60{ }^{\circ} \mathrm{C}$ to $0{ }^{\circ} \mathrm{C}$; (b) $\mathrm{Ph}_{2} \mathrm{SO}, \mathrm{TTBP}, \mathrm{CH}_{2} \mathrm{Cl}_{2},-60{ }^{\circ} \mathrm{C}$, then $\mathrm{Tf}_{2} \mathrm{O}, 46,-60{ }^{\circ} \mathrm{C}$ to $0{ }^{\circ} \mathrm{C}$.

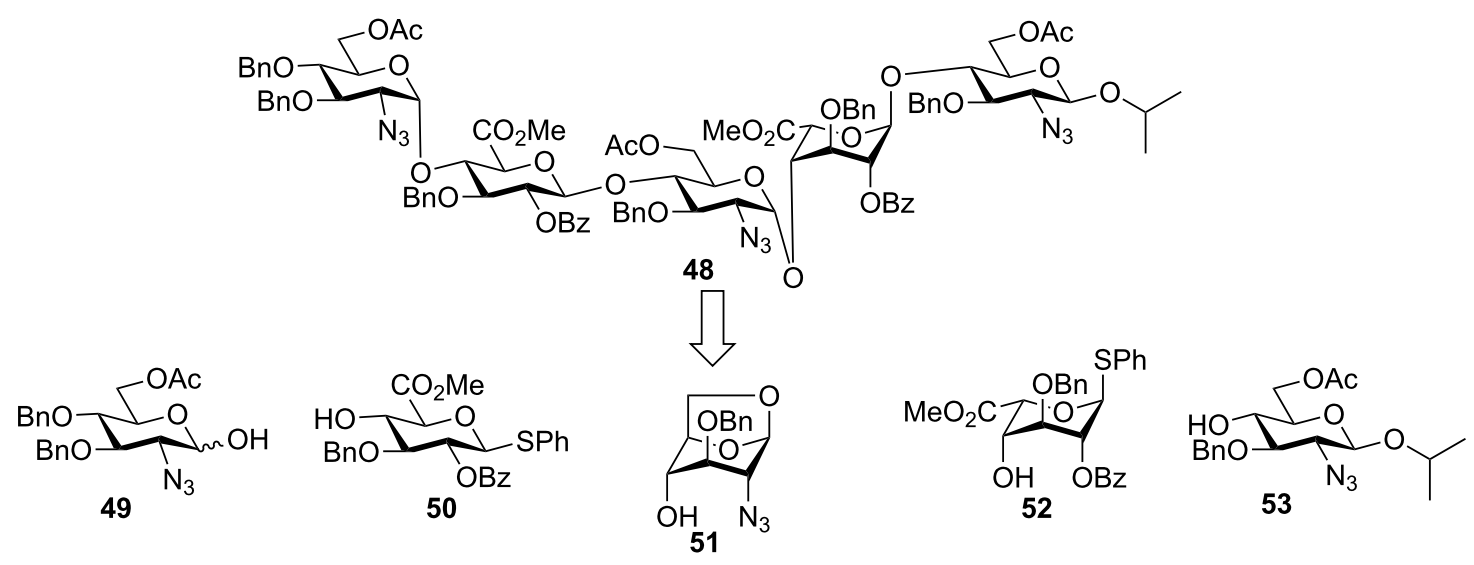

Figure 2: Retrosynthetic analysis of pentasaccharide 48.

donor and uronic acid thioglycosyl acceptor pairs were screened under preactivation conditions. The anomeric leaving groups of the acceptors had significant impacts on the glycosylation outcomes (Scheme 11a). When donor 54 was utilized to glycosylate iduronic acid $\mathbf{5 5}$, disaccharide $\mathbf{5 6}$ was obtained only in $31 \%$ yield along with aglycon transfer products, $57(19 \%)$ and 58 (24\%). The modest yield of the desired glycoside product resulted from the lower nucleophilicity of $4-\mathrm{OH}$ as compared to the thioethyl moiety, which could compete with the nucleophilic attack by the 4-OH leading to aglycon transfer (Scheme 11b). In contrast, when thiophenyl glycoside $\mathbf{5 2}$ was used as the acceptor, no aglycon transfer product was isolated and disaccharide 59 was obtained in $43 \%$ yield. The improvement presumably resulted from the lower nucleophilicity of the thiophenyl moiety due to the steric as well as electronegative effects of the phenyl group. The hemiacetal donor $\mathbf{4 9}$ glycosylated the thiophenyl glucuronate acceptor $\mathbf{5 0}$ in an excellent $91 \%$ yield using the preactivation protocol (Scheme 11c). The successful preparation of disaccharides 61 and 59 paved the way for the synthesis of protected heparin pentasaccharide $\mathbf{4 8}$ (Scheme 11d).

\section{Preactivation-based chemoselective glycosylation of thioglycosides}

Thioglycosides are one of the most commonly utilized building blocks due to their high stabilities under a wide range of synthetic transformations commonly encountered in building block preparation [41]. At the same time, mild promoters are available for thioglycoside activation. The anomeric reactivities of thioglycosides towards glycosylation can be significantly influenced by the protective groups on the glycan ring as well as the size and nucleophilicity of the thioether aglycon [42-44]. Extensive studies on how to fine tune anomeric reactivities culminated in the establishment of the powerful reactivity-based chemoselective glycosylation method [11]. In this strategy, a thioglycosyl donor with high anomeric reactivity is mixed together with a bifunctional thioglycosyl acceptor with lower anomeric reactivity (Scheme 12). Upon the addition of a promoter, the donor is preferentially activated to glycosylate the acceptor. The resulting disaccharide can then be utilized directly as a donor to react with another bifunctional thioglycoside with even lower anomeric reactivity. When building blocks with suitable anomeric reactivities are selected, multiple glycosyla- 

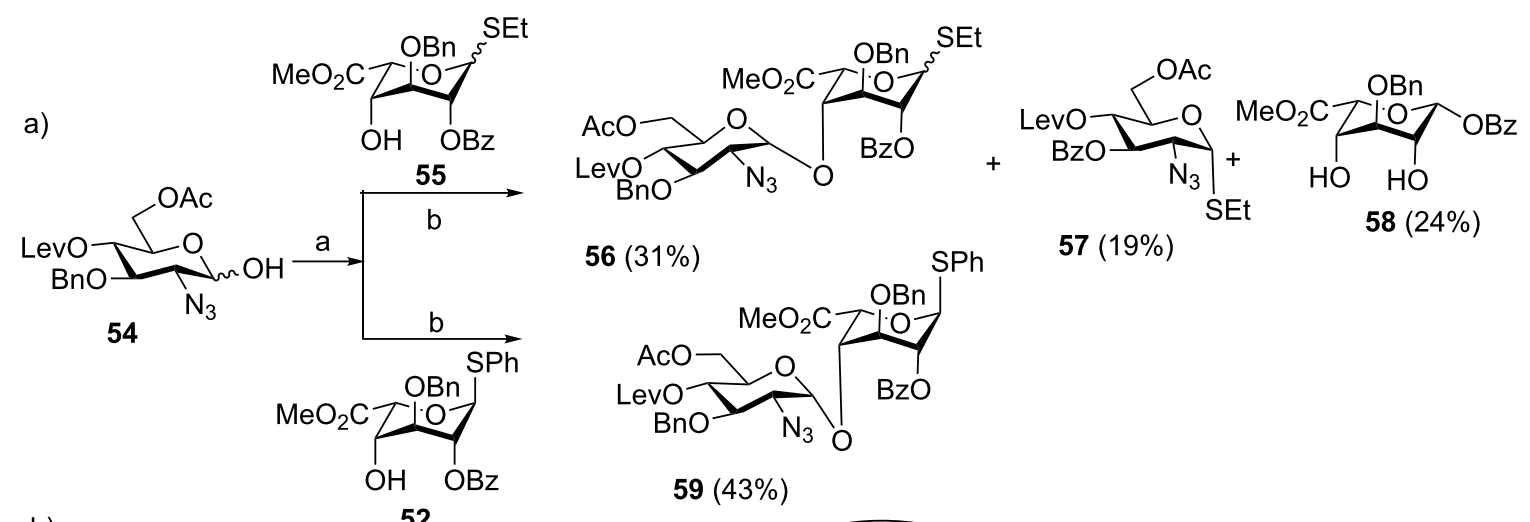

b)

52

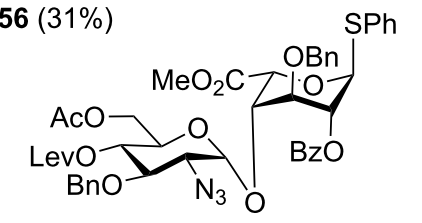

$7(19 \%)$

$59(43 \%)$

LevO

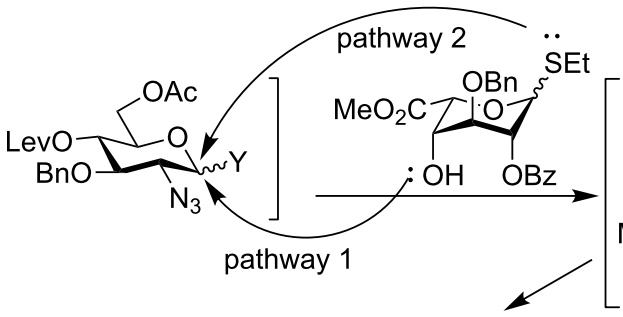

57

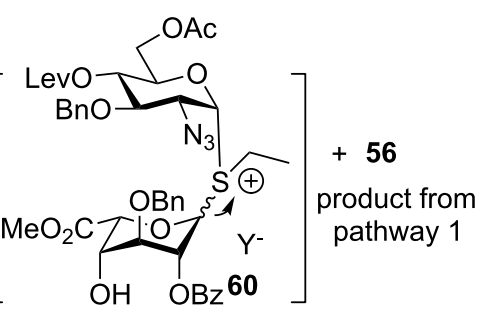

product from pathway 2

c)
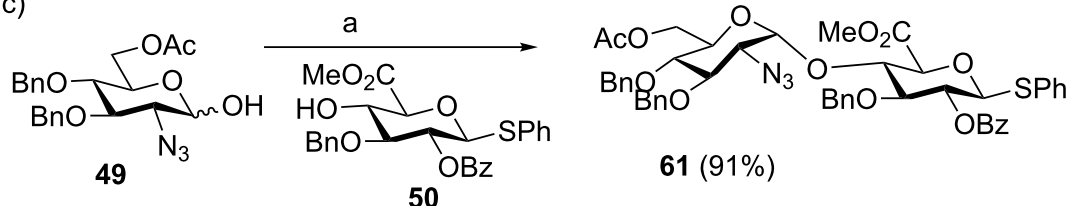

d) $\underset{51}{\stackrel{b}{\longrightarrow}}$

$62(76 \%)$

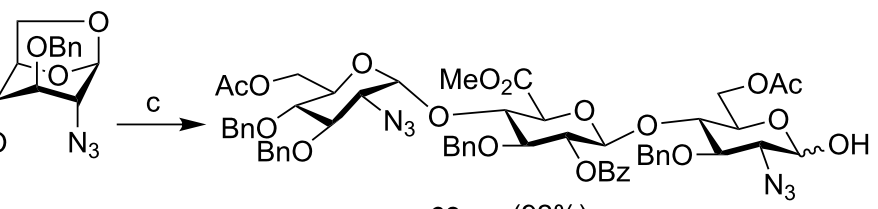

$63(92 \%)$

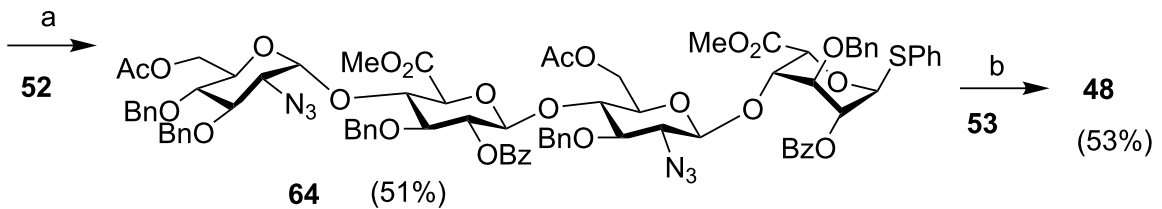

Scheme 11: Effects of anomeric leaving groups on glycosylation outcomes. Reagents and conditions: (a) $\mathrm{Ph}_{2} \mathrm{SO}, \mathrm{Tf} \mathrm{O}_{2} \mathrm{O}, \mathrm{TTBP}, \mathrm{CH}_{2} \mathrm{Cl}_{2},-40{ }^{\circ} \mathrm{C}$; then acceptor, $-40{ }^{\circ} \mathrm{C}$ to rt, (b) 1 -(benzenesulfinyl)piperidine, $\mathrm{Tf}_{2} \mathrm{O}, \mathrm{CH}_{2} \mathrm{Cl}_{2},-60{ }^{\circ} \mathrm{C}$, then acceptor, (c) $10 \%$ trifluoroacetic acid in $\mathrm{Ac}_{2} \mathrm{O}, 0{ }^{\circ} \mathrm{C}$ to $\mathrm{rt}$, then $6 \%$ piperidine in THF.

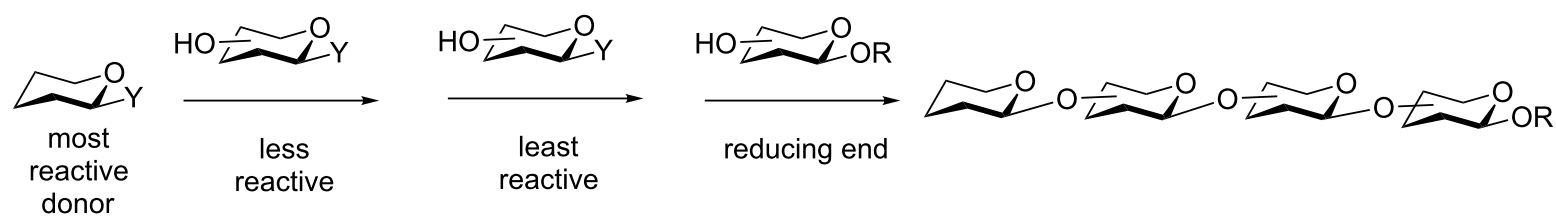

Scheme 12: Reactivity-based one-pot chemoselective glycosylation

tion reactions can be carried out in one pot without the need for synthetic manipulations or purification of the advanced oligosaccharide intermediates. This strategy, which has been covered in other reviews $[23,42]$, has been applied to successful synthesis of a range of complex oligosaccharides including human milk oligosaccharides [45], an embryonic stem cell surface 
carbohydrate marker Lc4 [46], Globo-H hexasaccharide [47], and heparin-like oligosaccharides [48].

A significant drawback of the reactivity-based chemoselective glycosylation method is the requirement that the glycosyl donor must bear higher anomeric reactivities than the acceptor for preferential donor activation. As a result, extensive protecting group manipulations have to be carried out to prepare building blocks with the required anomeric reactivities. Furthermore, the relative anomeric reactivity values of a building block can vary depending on the structures of acceptors and reaction condition [44], presenting challenges in accurately predicting the reaction outcome.

The aforementioned drawbacks of the reactivity-based chemoselective glycosylation can be overcome through preactivation. Under the preactivation protocol, a thioglycosyl donor is activated in the absence of an acceptor to form a reactive intermediate (Scheme 13). Upon complete donor activation, a thioglycosyl acceptor is added, which reacts with the intermediate to form the desired glycoside without the need for additional promoter. The resulting disaccharide bears a thioether aglycon, which can undergo another round of preactivation and glycosylation for rapid chain extension. As donor activation and acceptor glycosylation are carried out in two distinct steps, the preactivation strategy obviates the requirement that the glycosyl donor must have a higher anomeric reactivity than the acceptor for preferential activation, bestowing greater flexibilities in building block design.

A key consideration in designing successful preactivation-based thioglycoside glycosylation is the promoter. It needs to be able to activate a wide range of donors stoichiometrically rather than catalytically to avoid an undesired activation of the acceptor or the product. Many thiophilic activators have been tested, which include $p$-TolSCl/AgOTf [18], $N$-iodosuccinimide (NIS)/ TMSOTf [18], dimethyl(methylthio)sulfonium triflate (DMTST) [18], 1-(benzenesulfinyl)piperidine (BSP)/ $/ \mathrm{Tf}_{2} \mathrm{O}$ [18,19,49], $S$-(4-methoxyphenyl)benzene-thiosulfinate (MBPT)/ $\mathrm{Tf}_{2} \mathrm{O}$ [50], $\mathrm{Ph}_{2} \mathrm{SO} / \mathrm{Tf}_{2} \mathrm{O}$ [36,51], O,O-dimethylthiophosphonosulfenyl bromide (DMTPSB)/AgOTf [52], and 4-(benzenesulfinyl)morpholine (BSM)/ $\mathrm{Tf}_{2} \mathrm{O}$ [53].

The combination of $\mathrm{BSP} / \mathrm{Tf}_{2} \mathrm{O}[19,49]$ has been utilized as the promoter for iterative oligosaccharide synthesis including oligoglucosamine library [20], oligomannan [54] and Lewis ${ }^{a}$ trisaccharide [55]. During their synthesis, van der Marel and co-workers [19] found that with $\mathrm{BSP} / \mathrm{Tf}_{2} \mathrm{O}$ promoter, the glycosylation of donor $\mathbf{7 2}$ and acceptor $\mathbf{7 4}$ gave a moderate yield of $44 \%(\alpha: \beta=2: 1)$ of the desired product 75 (Scheme 14$)$. This was attributed to the formation of ( $N$-piperidino)phenyl( $S$-thioethyl)sulfide triflate (73) from the reaction of $\mathrm{BSP} / \mathrm{Tf}_{2} \mathrm{O}$

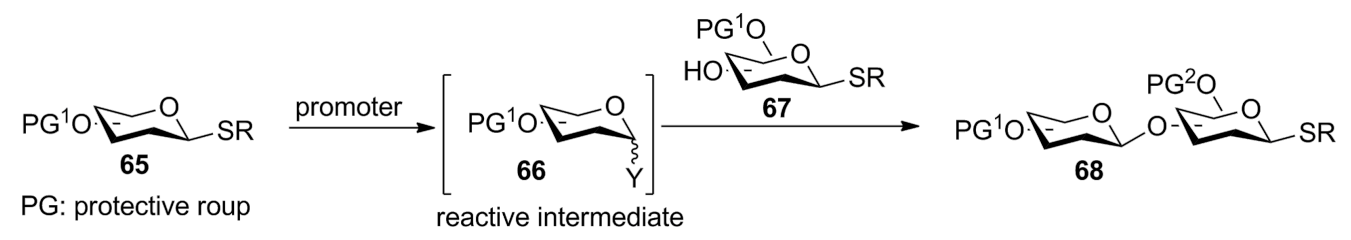

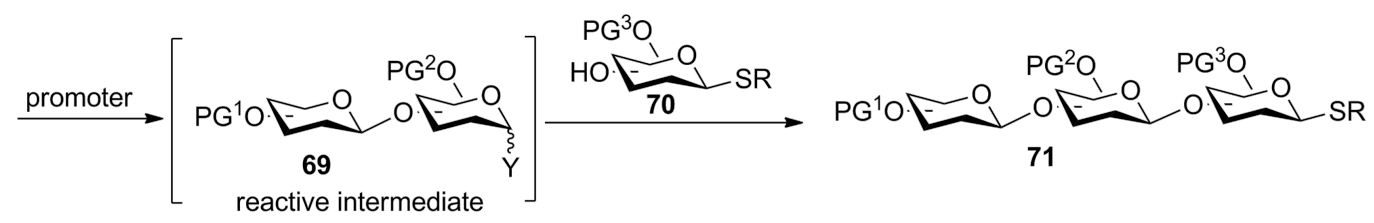

Scheme 13: Preactivation-based iterative glycosylation of thioglycosides.

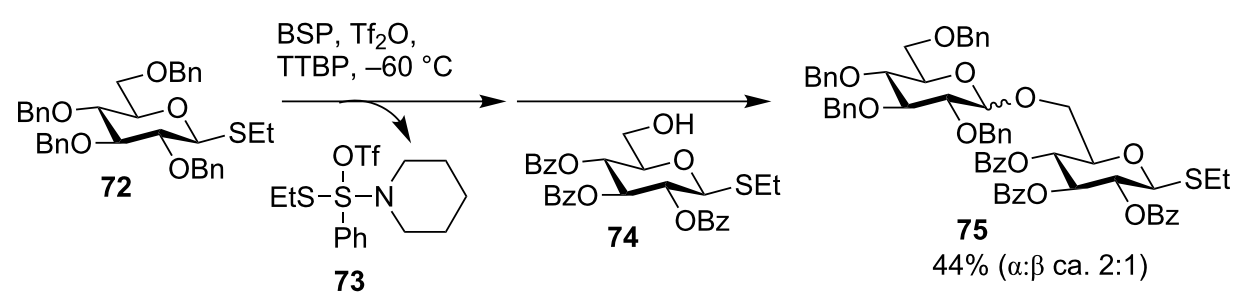

Scheme 14: BSP/Tf ${ }_{2} \mathrm{O}$ promoted synthesis of 75 . 
with the thioglycosyl donor. The sulfide triflate $\mathbf{7 3}$ could activate the thioglycoside product, which provides a possible explanation for the modest yield. To avoid the side reaction caused by $\mathbf{7 3}$, triethyl phosphite was added as a scavenger to quench 73, which enhanced the glycosylation yield to $78 \%$.

The need for triethyl phosphite to prevent the undesired acceptor/product activation precludes the possibility of carrying out multiple glycosylation reactions in one pot using $\mathrm{BSP} / \mathrm{Tf}_{2} \mathrm{O}$. Other promoter systems such as NIS/TMSOTf, $\mathrm{Ph}_{2} \mathrm{SO} / \mathrm{Tf}_{2} \mathrm{O}$ and $\mathrm{BSM} / \mathrm{Tf}_{2} \mathrm{O}$ have similar complications due to the formation of thiophilic or nucleophilic side products following donor activation. Through extensive experimentation, Huang, Ye and co-workers successfully developed an iterative one-pot glycosylation strategy using the $p$-TolSCl/AgOTf promoter system and $p$-tolyl thioglycosides as building blocks [18]. A possible mechanism for this glycosylation has been proposed (Scheme 15). Addition of $p$-TolSCl to the mixture of donor $\mathbf{7 6}$ and AgOTf forms $p$-TolSOTf, a powerful electrophile that can electrophilically add to the anomeric sulfur atom of $\mathbf{7 6}$ forming disulfonium ion 77 (step 1 in Scheme 15). After ejection of the ditolyl disulfide, 77 can evolve into several reactive species, such as oxocarbenium ion $\mathbf{7 9}, \alpha$-triflate $\mathbf{8 0}$, disulfonium ion $\mathbf{8 1}$, and dioxalenium ion $\mathbf{8 2}$. The nucleophilic attack of the intermediate by a thioglycosyl acceptor would generate the desired glycoside $\mathbf{7 8 .}$

Pioneered by Crich and co-workers, low temperature NMR studies have been found to be a powerful approach to analyze intermediates formed during glycosylation reactions [56]. To determine the dominant intermediate in preactivation of thiogly- cosides, low-temperature an NMR experiments were carried out following donor activation [57]. It was determined that with perbenzoylated donor $\mathbf{8 3}$, the $\alpha$-glycosyl triflate $\mathbf{8 4}$ was formed as the major intermediate $[56,58,59]$. When the more electronrich donor 85 was preactivated, the dioxalenium ion 86 via the participation of the 2-benzoyl (Bz) group was found as the dominating species from NMR analysis (Figure 3) [57]. Interestingly, when $\mathbf{8 7}$ was preactivated, two major intermediates were produced ( $\alpha$-triflate $\mathbf{8 8}$ and dioxalenium ion $\mathbf{8 9}$ ). The different outcome upon preactivation can be explained in terms of different electron-withdrawing properties of the protective groups present in these three donors. For 83, the Bz group greatly disfavors the formation of a positively charged dioxalenium ion while the electron-donating benzyl (Bn) group can stabilize the dioxalenium ion. Donor $\mathbf{8 7}$ presents an intermediate case. The absence of the disulfonium ion $\mathbf{8 1}$ following the donor activation confirms that the disulfide does not significantly impact the structure of the intermediates. The more electron-rich glycosyl donors were found to give higher yields in glycosylation, especially with unreactive and electron-poor secondary acceptors. A representative example is shown in Scheme 16. This was rationalized by higher reactivities of the dioxalenium ion than glycosyl triflate towards nucleophilic attack by the acceptor.

$p$-TolSCl/AgOTf is a superior promoter system for the preactivation-based thioglycoside glycosylation. Some reactions that failed with the $\mathrm{BSP} / \mathrm{Tf}_{2} \mathrm{O}$ promoter could be successfully performed with similar substrates using $p$-TolSCl/AgOTf (Scheme 17). This is presumably due to the inertness of the ditolyl disulfide side product from $p$-TolSCl/AgOTf promoted activation, which does not interfere with glycosylation.

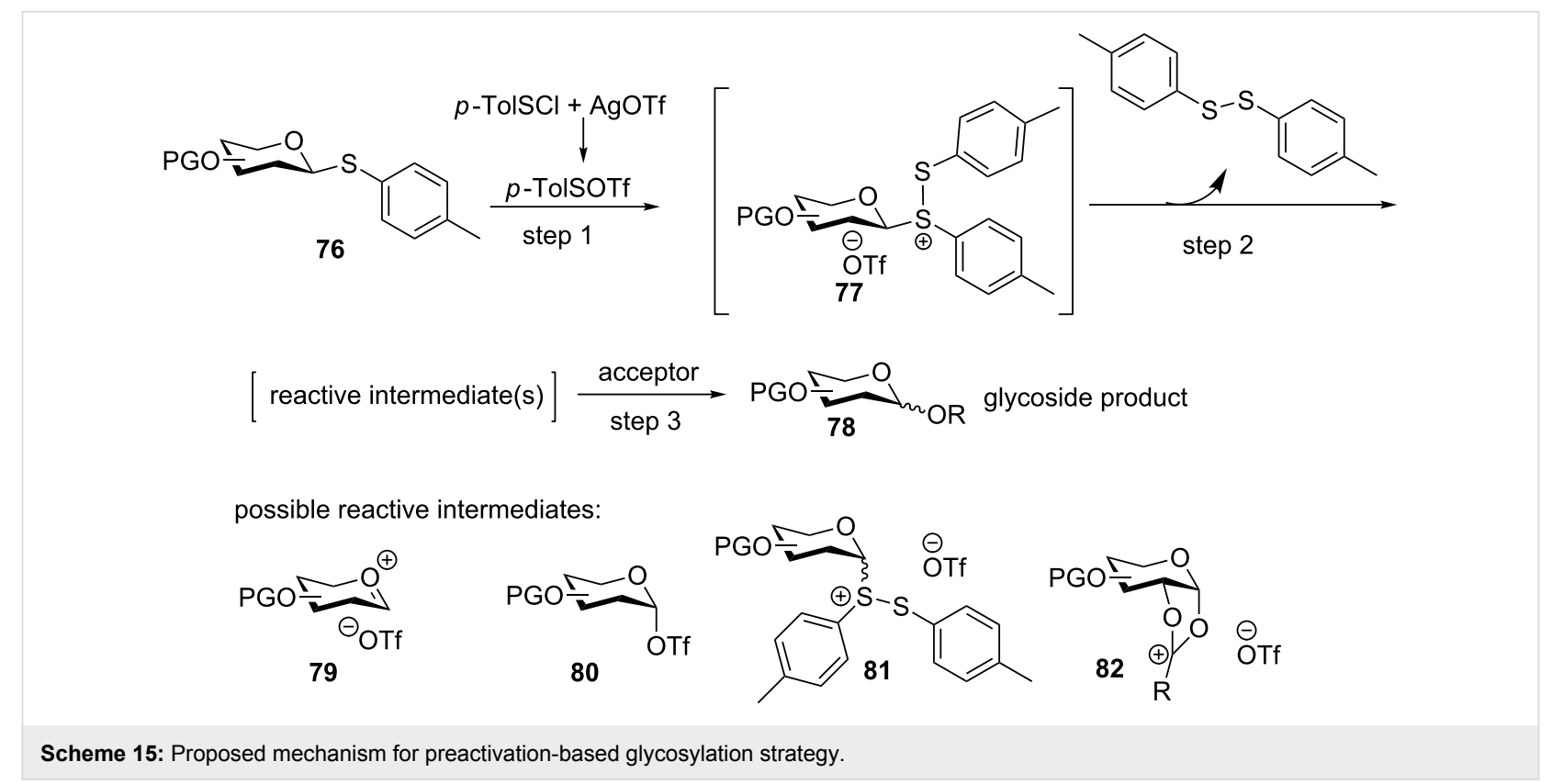



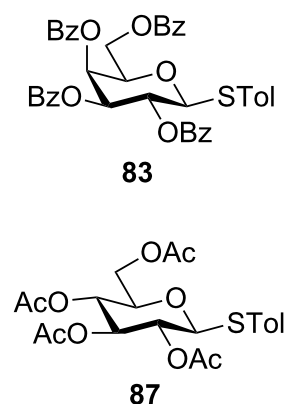
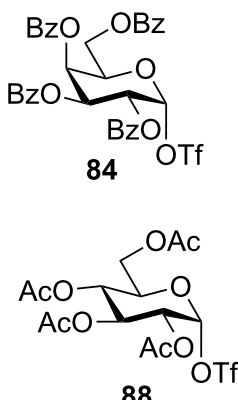

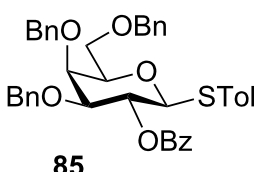

85

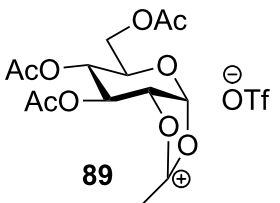

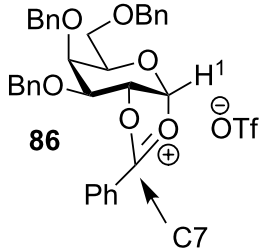

a)

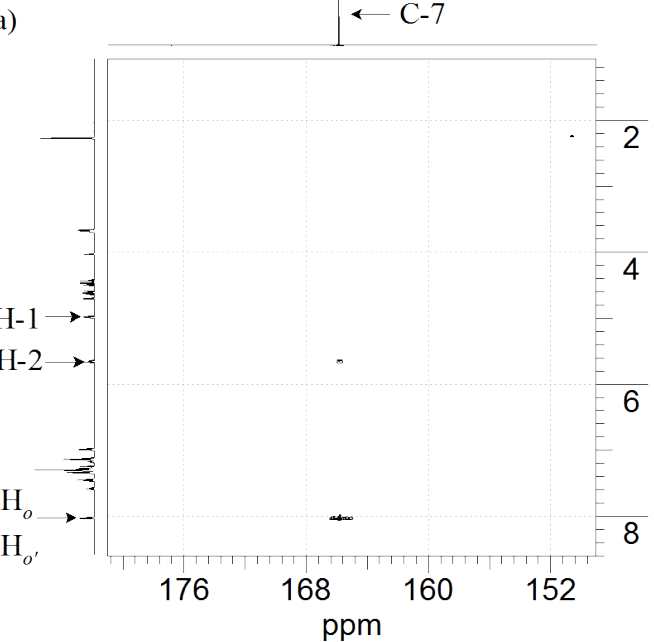

b)

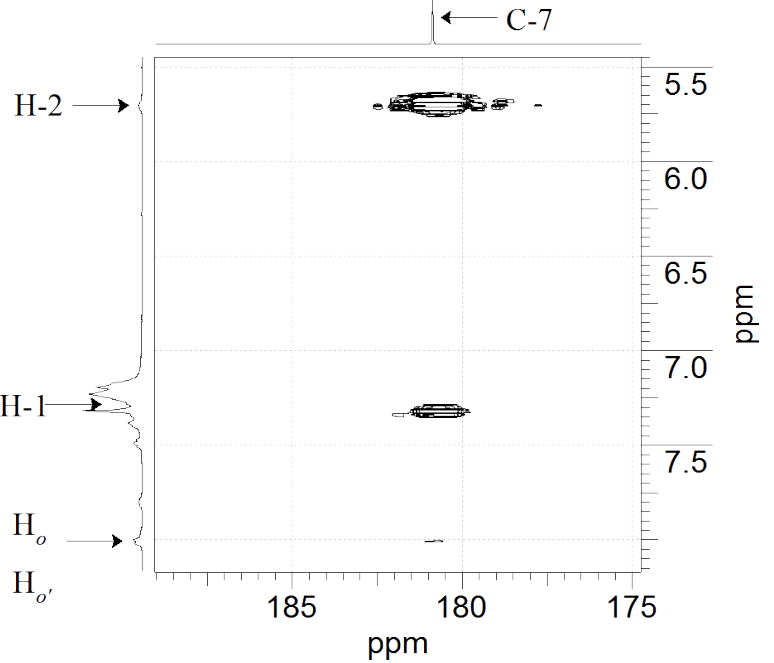

Figure 3: The preactivations of glycosyl donors $\mathbf{8 3}, \mathbf{8 5}$ and $\mathbf{8 7}$ were investigated by low temperature NMR, which gave $\mathbf{8 4 ,} \mathbf{8 6}, \mathbf{8 8 / 8 9}$ as dominant intermediates, respectively. gHMBC $\left(\mathrm{CDCl}_{3}, 600 \mathrm{MHz}\right)$ of donor $\left.85 \mathrm{a}\right)$ before and b) after preactivation at $-60^{\circ} \mathrm{C}$. The correlation peak emerged after activation between $\mathrm{C}-7$ and $\mathrm{H}-1$ supports the structure of the dioxalenium ion $\mathbf{8 6}$ formed from preactivation.

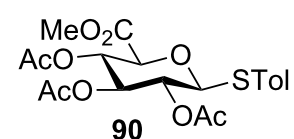

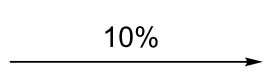

90

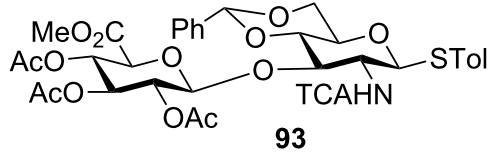

93

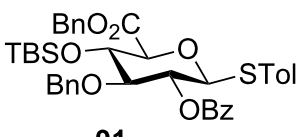

91

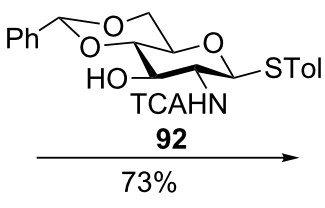

94

Scheme 16: The more electron-rich glycosyl donor 91 gave a higher glycosylation yield than the glycosyl donor 90 bearing more electron-withdrawing acyl protective groups.

The $p$-TolSCl/AgOTf-promoted preactivation glycosylation has been successfully applied to the total synthesis of complex oligosaccharides including those containing both 1,2-cis and 1,2-trans linkages, branching sequences and sulfate esters. For example, a four component preactivation-based one-pot synthesis was designed to synthesize Globo- $\mathrm{H}$, an important tumor-associated carbohydrate antigen (Scheme 18) [60]. Globo-H hexa- saccharide 105 was prepared within 7 hours in an excellent overall yield of $47 \%$ from the sequential one-pot reaction of 101, 102, 103 and 104. Compared to the automated solid-phase synthesis of Globo-H [61], the solution-based preactivationbased synthesis gave a higher overall yield for glyco-assembly ( $47 \%$ vs 30\%) without the need for large excess (5-10 equiv) of building blocks. 

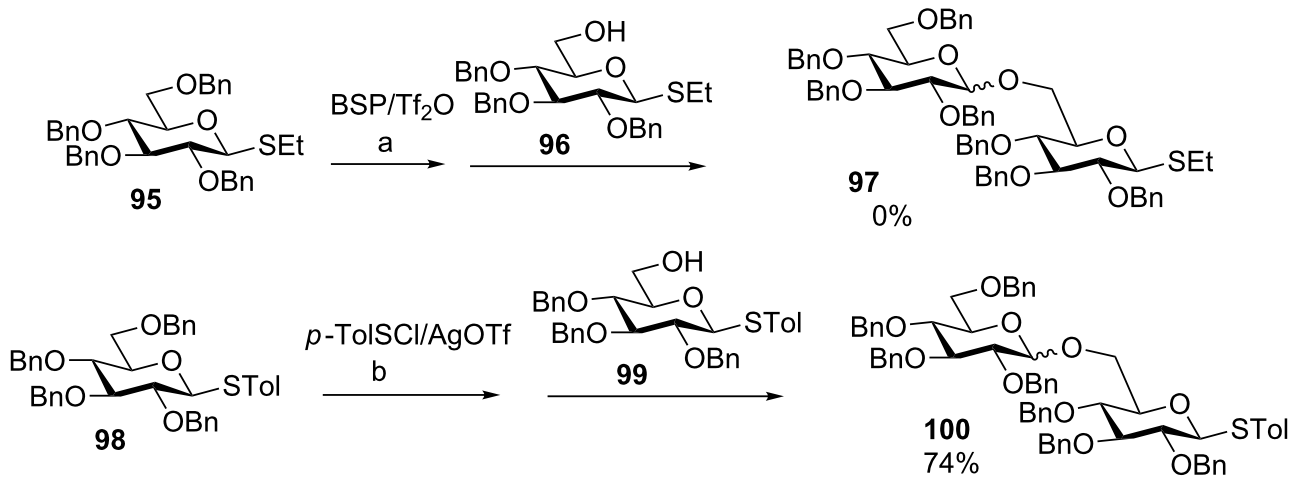

Scheme 17: Comparison of the $\mathrm{BSP} / \mathrm{Tf}_{2} \mathrm{O}$ and $p$-TolSCl/AgOTf promoter systems in facilitating the preactivation-based thioglycoside glycosylation Reagents and conditions: (a) BSP, $\mathrm{Tf}_{2} \mathrm{O}, \mathrm{CH}_{2} \mathrm{Cl}_{2}$, TTBP, $-60^{\circ} \mathrm{C}$; then 96 , and triethyl phosphite; (b) $p$ - TolSCl/AgOTf, $-60{ }^{\circ} \mathrm{C}$; then 99 .
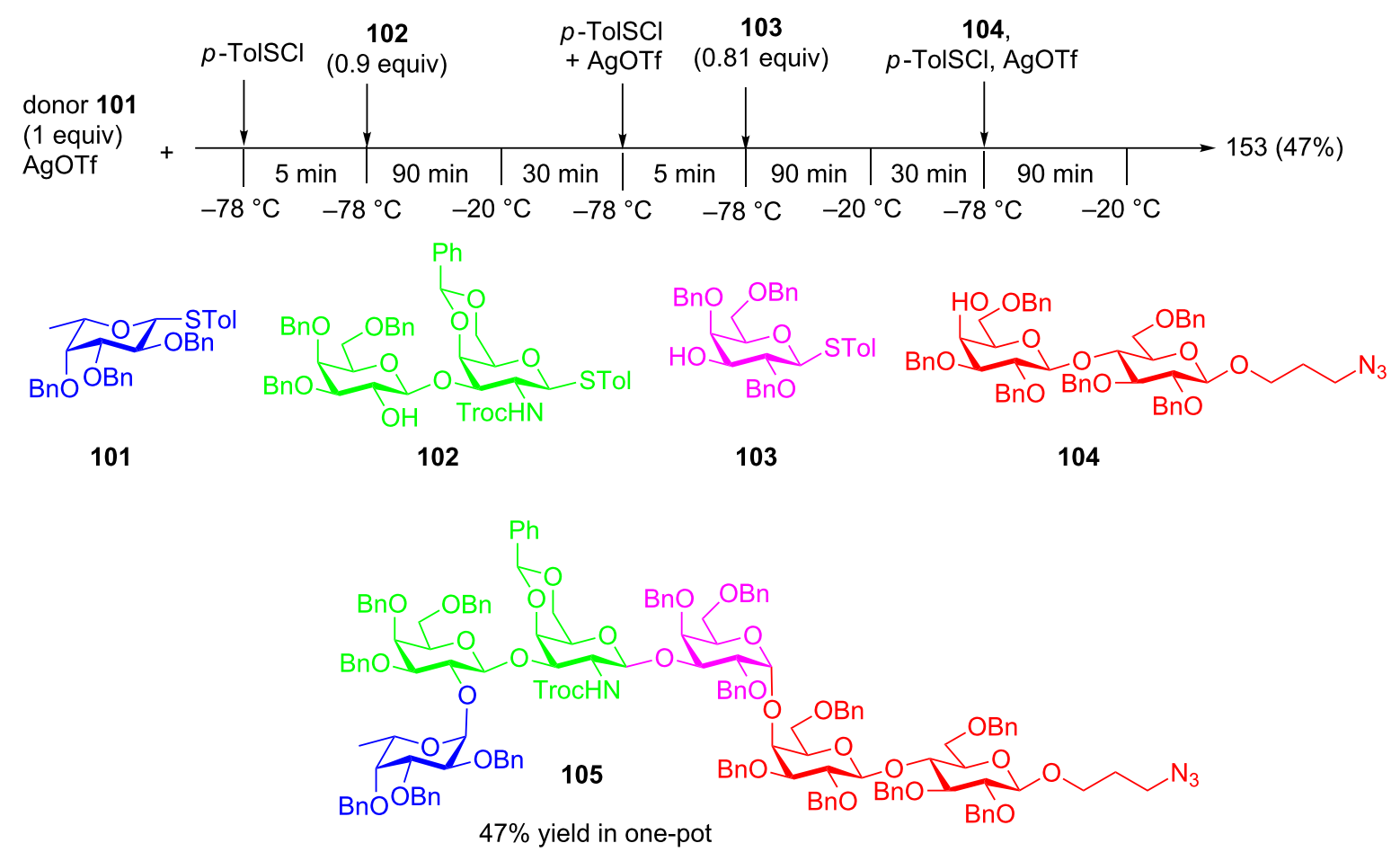

Scheme 18: One-pot synthesis of Globo-H hexasaccharide 105 using building blocks 101, 102, 103 and 104

Recently, using a series of highly efficient preactivation-based glycosylation reactions, Ye and co-workers synthesized a mycobacterial arabinogalactan [62], which is composed of 30 D-galactofuranose residues $\left(\mathrm{Gal} f_{30}\right)$ linked with two arabinan chains each containing $31 \mathrm{D}$-arabinofuranose residues ( $\left.\operatorname{Ara} f_{31}\right)$. Both Gal $f_{30}$ and $\mathrm{Ara}_{31}$ fragments were prepared starting from monosaccharide building blocks. As an example, a six component preactivation-based glycosylation using the $p$-TolSCl/ AgOTf promoter system and three monosaccharide building blocks (106-108) led to the formation of hexasaccharide 109 in an excellent $63 \%$ yield in one pot on a gram scale
(Scheme 19a). This is the largest number of glycosylation reactions that have been performed in one pot to date. Further iterative five-component one-pot glycosylation (111+ $110+110+110+113)$ successfully produced protected Gal $f_{30}$ 30-mer 114 in 68\% yield (Scheme 19b). Following similar reaction protocols, Ara $f_{31}$ was prepared, which upon glycosylation of a Gal $f_{30}$ diol acceptor and deprotection, led to arabinogalactan 92-mer 116 (Figure 4) [62]. This is the largest synthetic glycan that has ever been produced, highlighting the power of the preactivation-based glycosylation strategy. 
a)

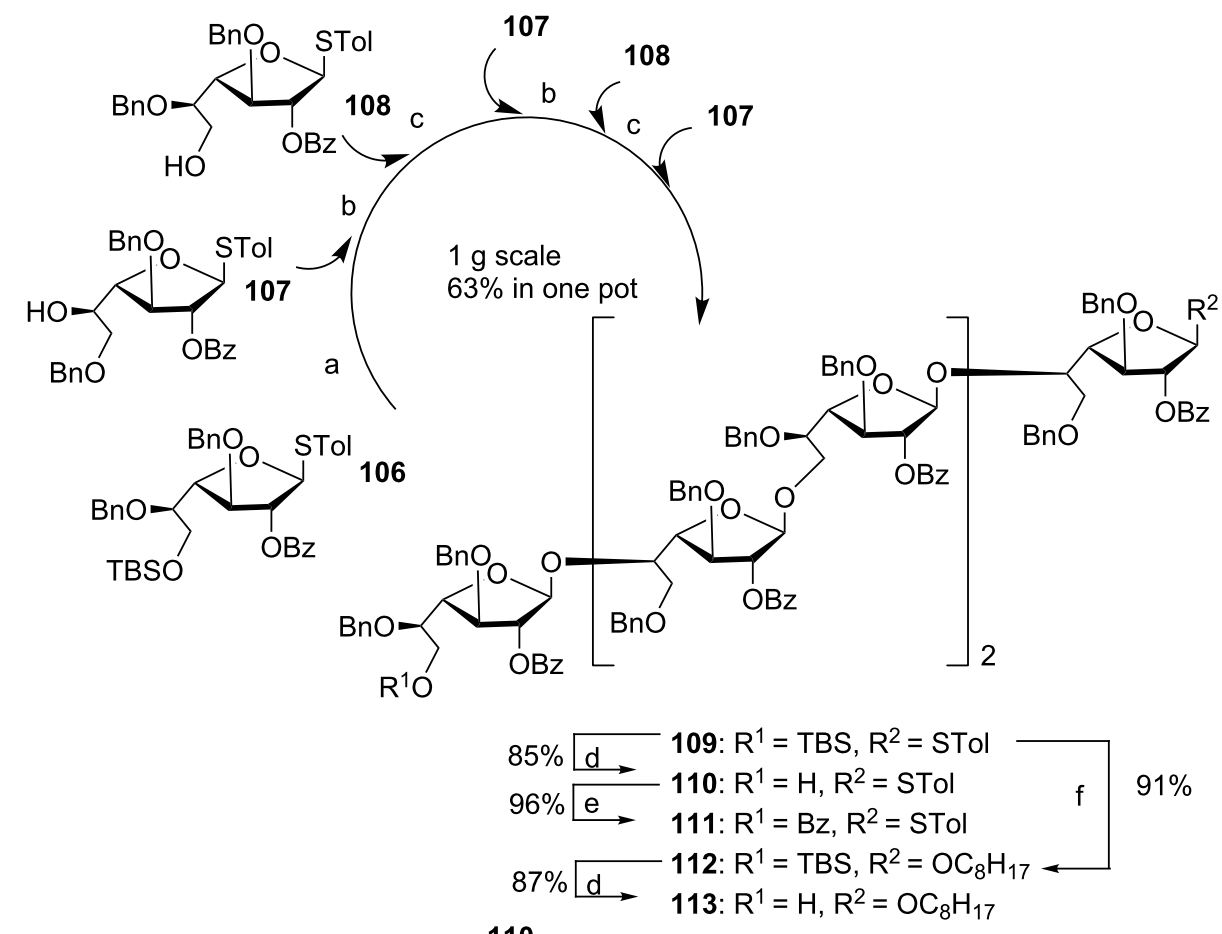

b)

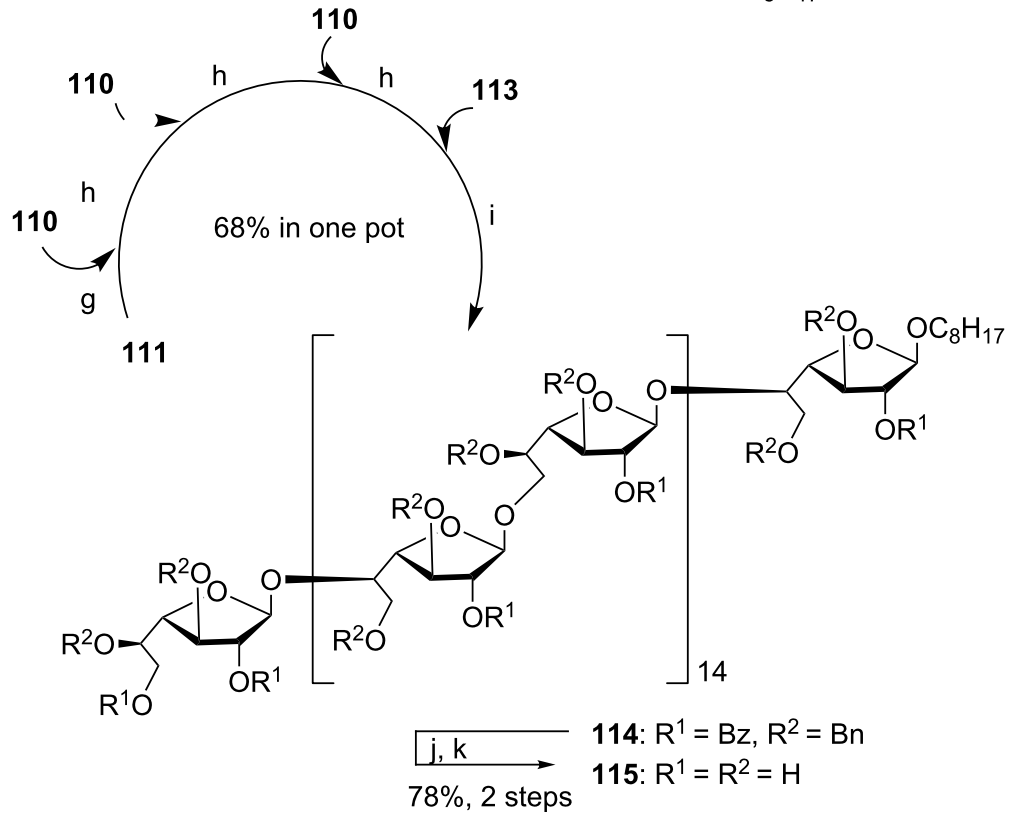

Scheme 19: Synthesis of (a) oligosaccharides 109-113 towards (b) 30-mer galactan 115. Reagents and conditions: (a) TTBP, $4 \AA$ MS, $\mathrm{CH}_{2} \mathrm{Cl}_{2}$, p-TolSCl, AgOTf, then 107, $-78{ }^{\circ} \mathrm{C}$ to rt; (b) p-TolSCl, AgOTf, then $108,-78{ }^{\circ} \mathrm{C}$ to rt; (c) $p$-TolSCl, AgOTf, then $107,-78{ }^{\circ} \mathrm{C}$ to rt; (d) HF-pyridine, $\mathrm{THF} / \mathrm{H}_{2} \mathrm{O}$ (10:1), $35^{\circ} \mathrm{C}$; (e) $\mathrm{Bz}{ }_{2} \mathrm{O}$, DMAP, pyridine, $\mathrm{CH}_{2} \mathrm{Cl}_{2}$, reflux; (f) $p$-TolSCl, AgOTf, TTBP, 1-octanol, $4 \AA \mathrm{MS}^{\circ} \mathrm{CH}_{2} \mathrm{Cl} 2,-78{ }^{\circ} \mathrm{C}$; (g) TTBP, $4 \AA \mathrm{MS}$, $\mathrm{CH}_{2} \mathrm{Cl}_{2}, p$-TolSCl, AgOTf, then $110,-78^{\circ} \mathrm{C}$ to rt; (h) $p$-TolSCl, AgOTf, then $110,-78{ }^{\circ} \mathrm{C}$ to rt; (i) $p$-TolsCl, $\mathrm{AgOTf}$, then $113,-78{ }^{\circ} \mathrm{C}$ to rt; (j) $\mathrm{NaOCH}$, $\mathrm{CH}_{3} \mathrm{OH} / \mathrm{CH}_{2} \mathrm{Cl}_{2}$ (2:1); (k) Pd/C, $\mathrm{H}_{2}$, EtOAc/THF/1-PrOH/ $\mathrm{H}_{2} \mathrm{O}(2: 1: 1: 1)$.

In addition to Globo-H 105 and arabinogalactan 116, other complex oligosaccharides obtained by the preactivation-based thioglycoside method include branched oligosaccharides from glycolipid family including Lewis ${ }^{\mathrm{X}}$ pentasaccharide $\mathbf{1 1 7}$, dimeric Lewis ${ }^{X} 118$ [63], tristearoyl lipomannan 119 [64], gangliosides GM1 120 [65] and GM2 121 (Figure 5) [66], microbial glycans such as the heptasaccharide repeating unit of type V group B Streptococcus capsular polysaccharide $\mathbf{1 2 2}$ 


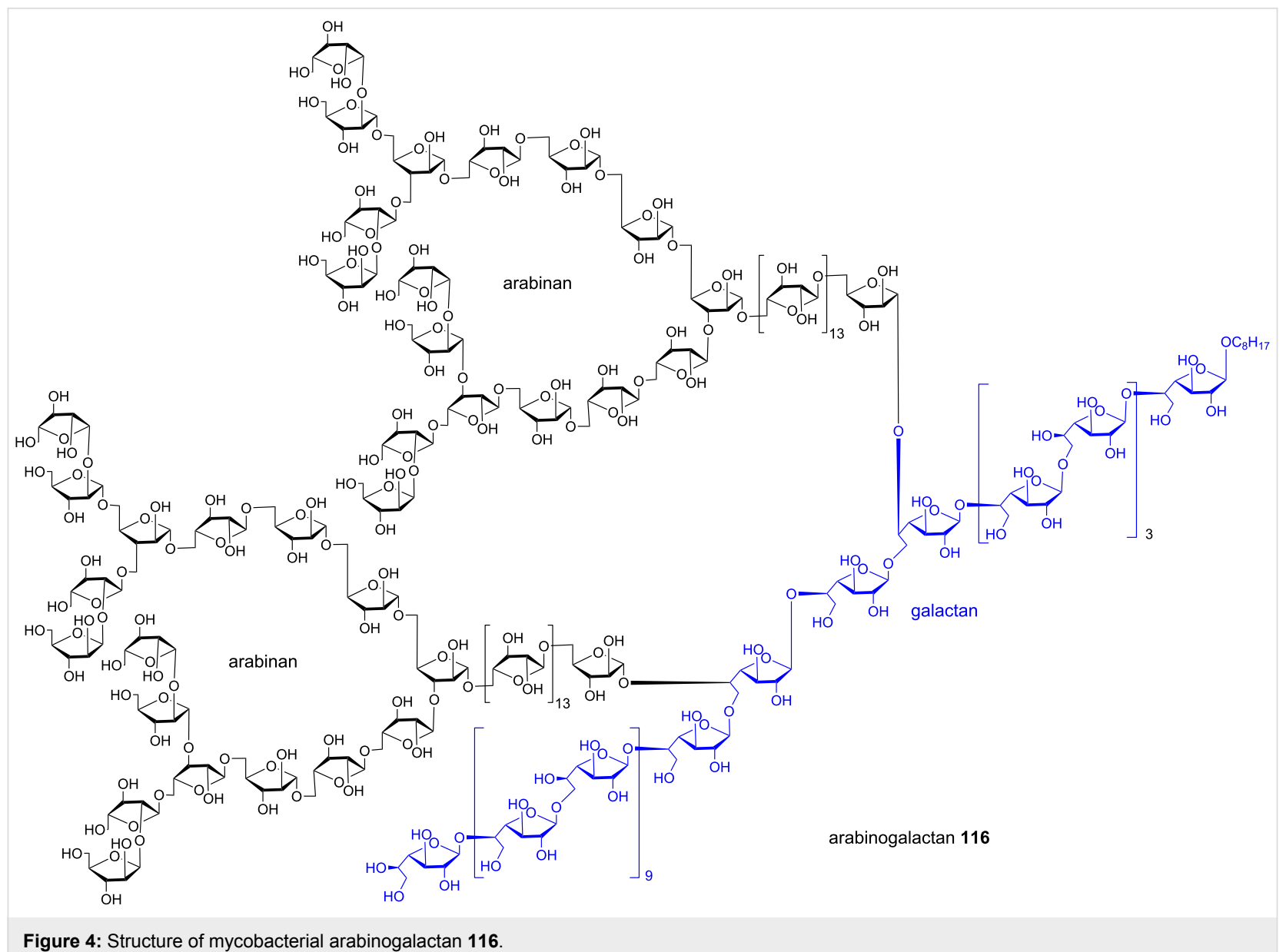

[67], $\beta$-glucan oligosaccharides 123 from fungal cells [68,69], oligomannan containing multiple challenging $\beta$-mannosyl linkages 124 [54] (Figure 6), chitotetraose [70], mammalian glycans including complex type bisected N-glycan dodecasaccharide 125 [71], glycosaminoglycans including hyaluronic acid oligosaccharides 126 [72,73] (Figure 7), and heparan sulfate oligosaccharides including those bearing sulfate esters $[74,75]$ and other sialylated glycans $[76,77]$.

As the preactivation-based glycosylation does not require the donor to have higher anomeric reactivity than the acceptor, this approach is particularly suitable for the synthesis of libraries of oligosaccharides by divergently combining building blocks. An example of this is the preparation of a library of heparan sulfate oligosaccharides (Figure 8) [74]. Alternating use of disaccharide building blocks 127 and 128 in preactivation-based one-pot glycosylation led to a panel of 7 heparan sulfate hexasaccharides 129-135 following the standard glycosylation protocol. The yields for one-pot glycosylation of all these hexasaccharides range from $50 \%$ to $70 \%$ highlighting the robustness of the protocol.
Besides the more "classical" chemical activation of thioglycosides, Nokami, Yoshida and co-workers developed an alternative method taking advantage of electrochemistry for donor activation [59]. They have demonstrated that thioglycosides can be electrochemically oxidized in the presence of tetrabutylammonium triflate to yield a glycosyl triflate, which can be subsequently glycosylated. This approach has been adapted to an automated solution-phase synthesis of poly- $\beta$-D-(1-6)- $N$-acetylglucosamine [78]. The aryl group in arylthioglycosides was first optimized for both the donor and the acceptor, where the electron-withdrawing fluorine on the phenyl ring gave the best result. The thioglycoside donor $\mathbf{1 3 6}$ was preactivated through anodic oxidation, followed by the addition of the acceptor 137 to afford disaccharide 138 (Scheme 20). Repeating this process, a series of oligo-glucosamine ranging from tri- to hexa-saccharides 139-142 was successfully prepared.

2-Deoxy and 2,6-dideoxyglycosides are present in many natural products. Based on the preactivation protocol, the Wang group reported a stereoselective glycosyl chloride-mediated synthesis of 2-deoxyglucosides [79]. They found that the addition of AgOTf and $p$-TolSCl to donor $\mathbf{1 4 3}$ afforded the stable glycosyl 

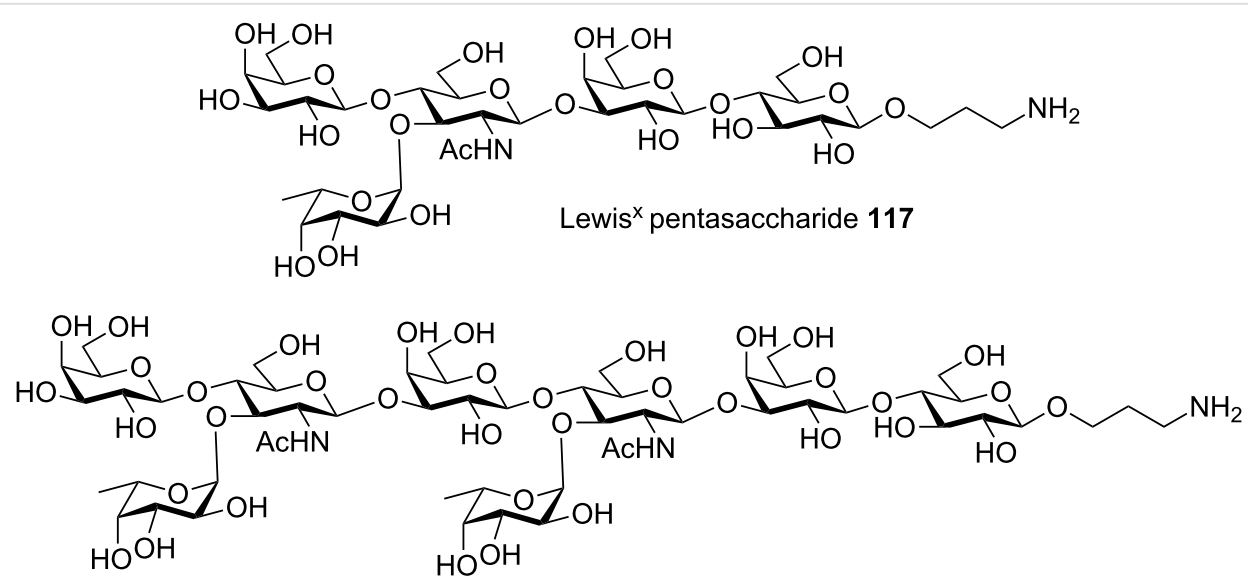

dimeric Lewis ${ }^{\mathrm{x}}$ octasaccharide 118
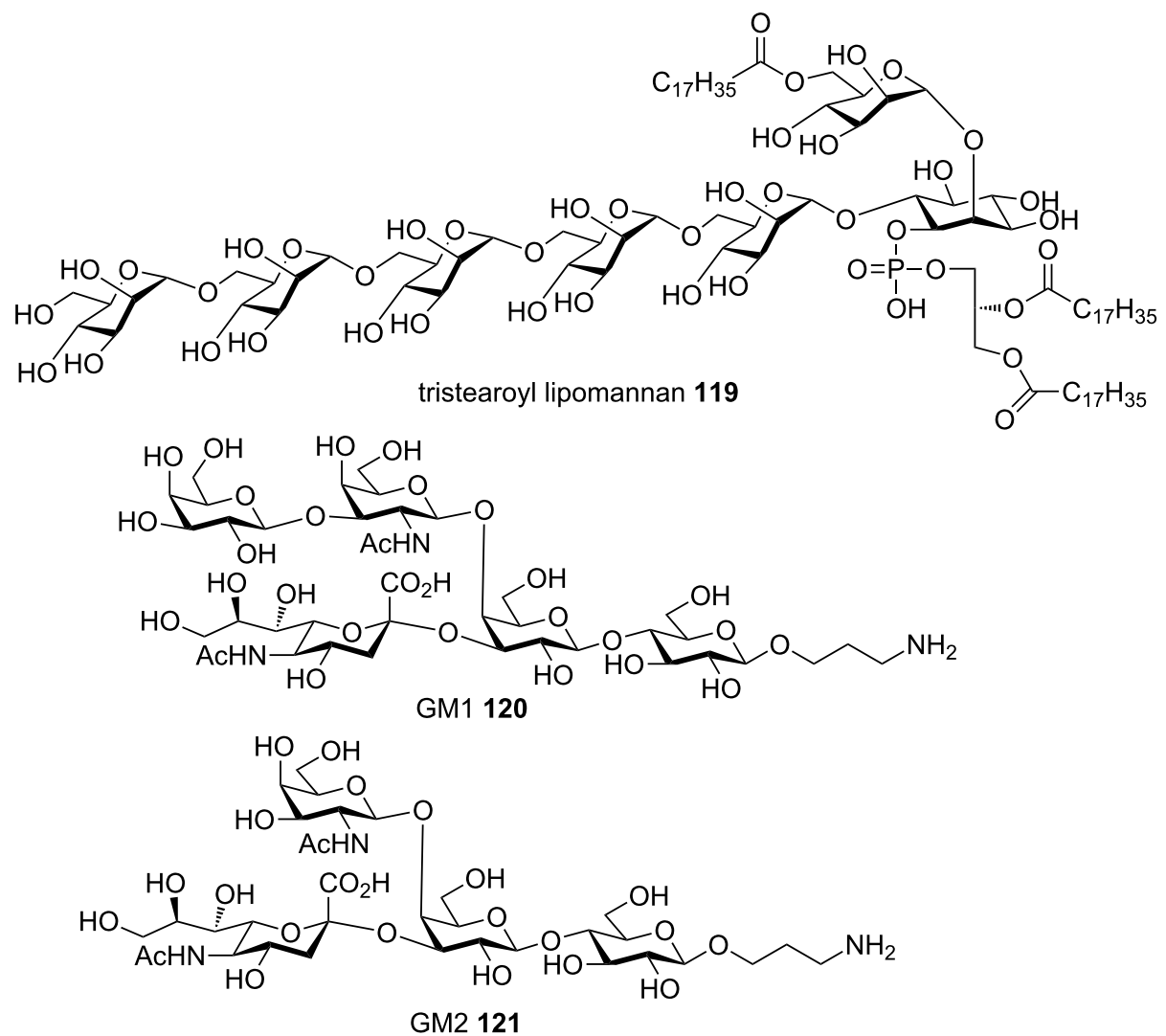

Figure 5: Representative complex glycans from glycolipid family synthesized by the preactivation-based thioglycoside method.

chloride 144 as detected by NMR (Scheme 21a). The formation of the glycosyl chloride was possibly due to the presence of Lewis basic molecule sieves (MS $4 \AA$ ) in the reaction system lowering the reactivity of AgOTf [18]. As a result, $p$-TolSCl could directly activate the glycosyl donor forming glycosyl chloride due to the higher anomeric reactivities of deoxy glycosides compared to the corresponding pyranosides. Upon the addition of the acceptor, the glycosyl chloride could be activated by AgOTf producing the glycosylation product with good $\alpha$ selectivity. To test the applicability to iterative synthesis, donor 143 was preactivated with $p$-TolSCl and AgOTf at $-78^{\circ} \mathrm{C}$ followed by the addition of acceptor 146 to afford disaccharide 147 in $70 \%$ yield with complete $\alpha$ selectivity (Scheme 21b). This high $\alpha$ selectivity remained when disaccharide 147 was reacted with acceptor 148 to give trisaccharide 149 using the same promoter system.

The preactivation-based one-pot approach can greatly accelerate oligosaccharide assembly. To facilitate isolation of the desired product from the reaction mixture, the Huang group re- 


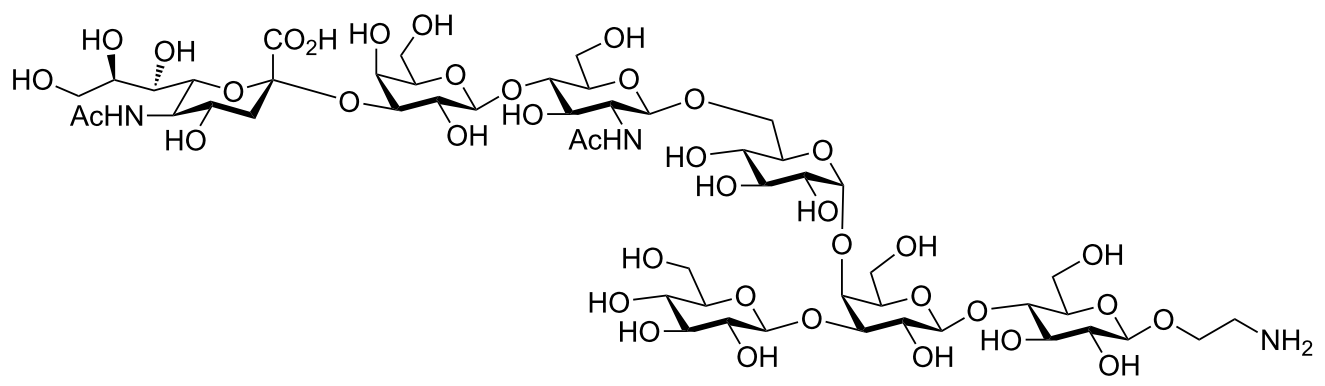

heptasaccharide repeating unit of type $V$ group B Streptococcus capsular polysaccharide 122

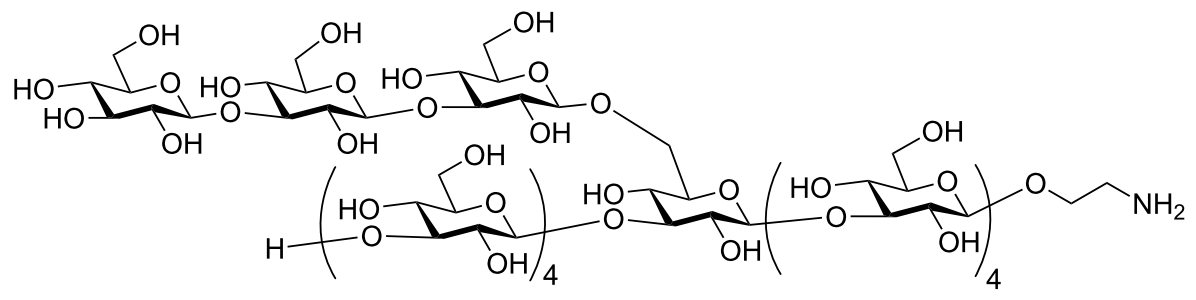

branched $\beta$-glucan oligosaccharide 123

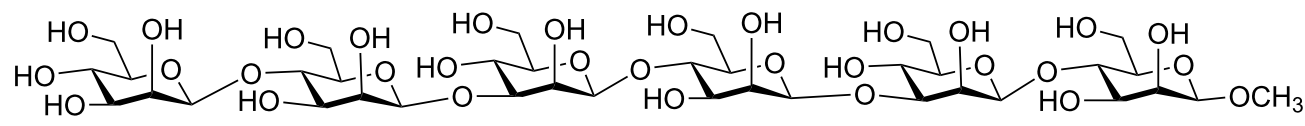

oligomannan 124 containing multiple challenging $\beta$-mannosyl linkages

Figure 6: Representative microbial and mammalian oligosaccharides synthesized by the preactivation-based thioglycoside method.

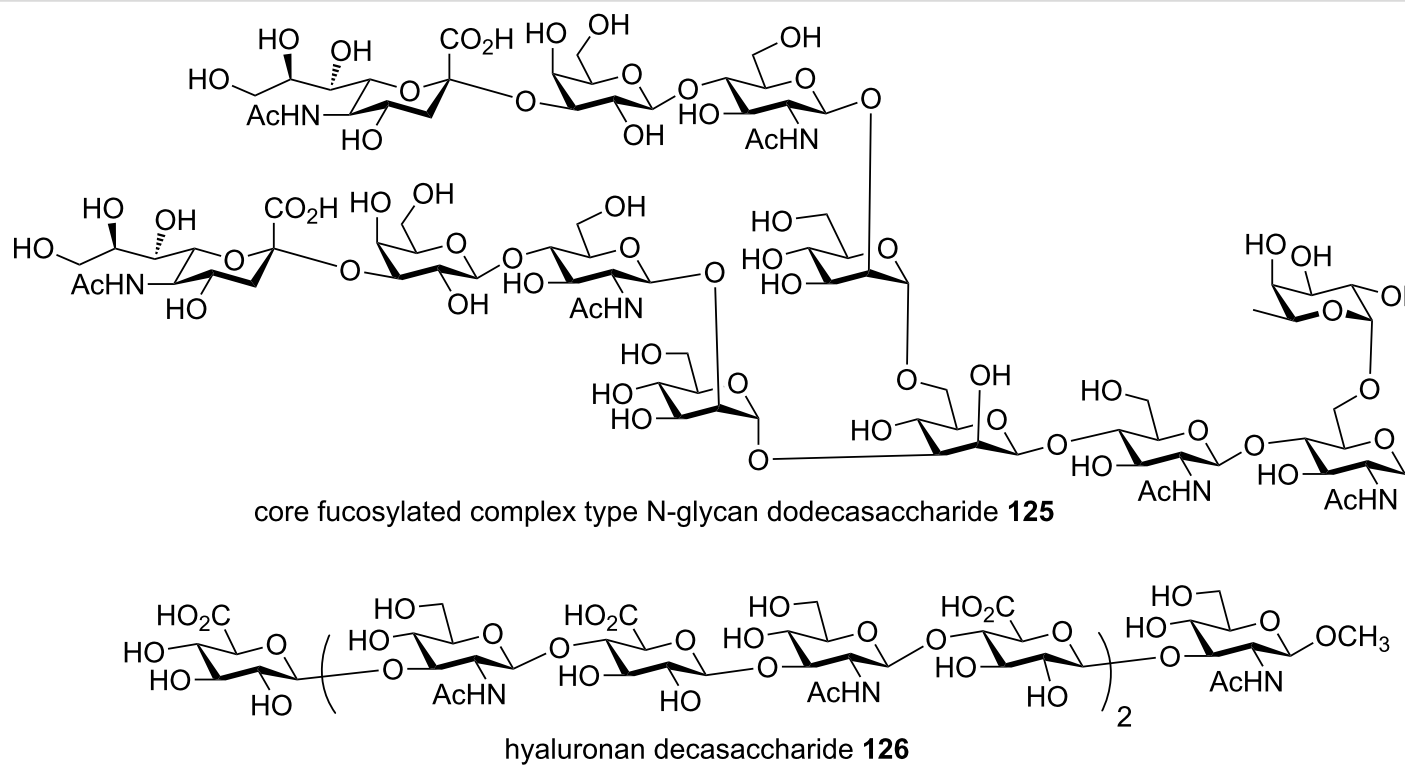

Figure 7: Some representative mammalian oligosaccharides synthesized by the preactivation-based thioglycoside method.

ported a fluorine-assisted one-pot method, where no silica gel column chromatography was required [80]. To demonstrate the applicability of this method, a linear tetrasaccharide was synthe- sized bearing a ketone tag at the reducing end using building blocks 83, 150 and 151 following the preactivation-based onepot protocol (Scheme 22). After completion of the synthesis, a 


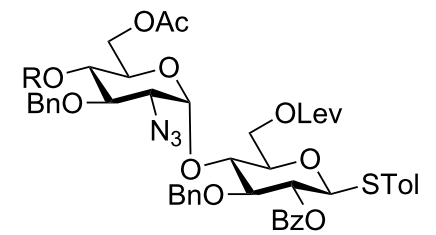

$127(\mathrm{R}=\mathrm{Bn}$ or $\mathrm{H})$

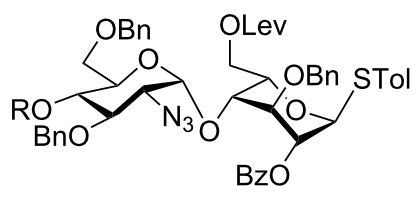

$128(\mathrm{R}=\mathrm{Bn}$ or $\mathrm{H})$

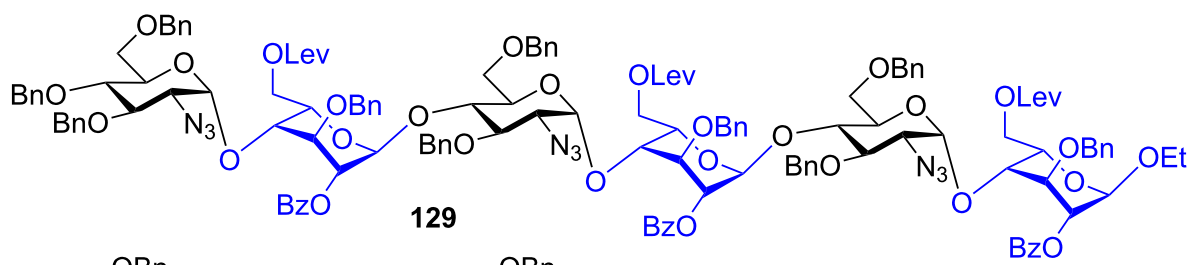

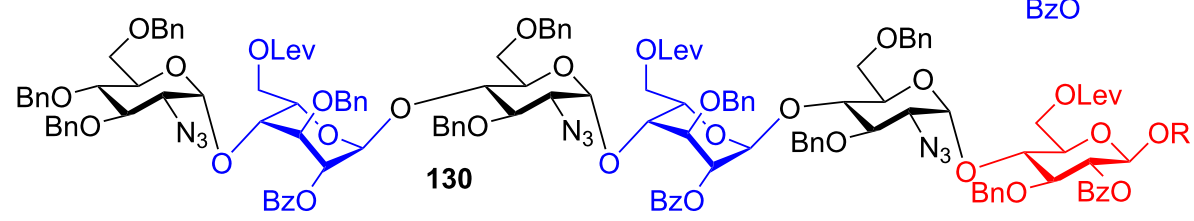

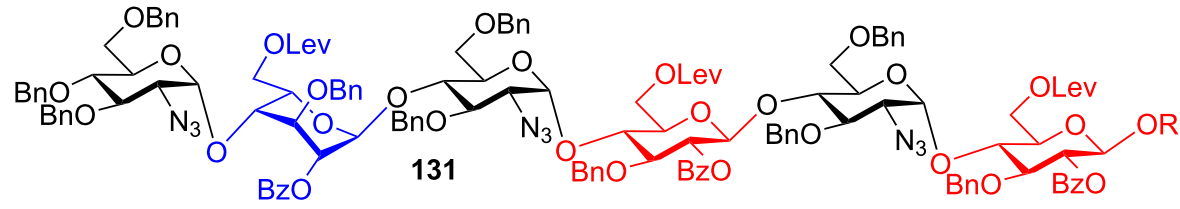

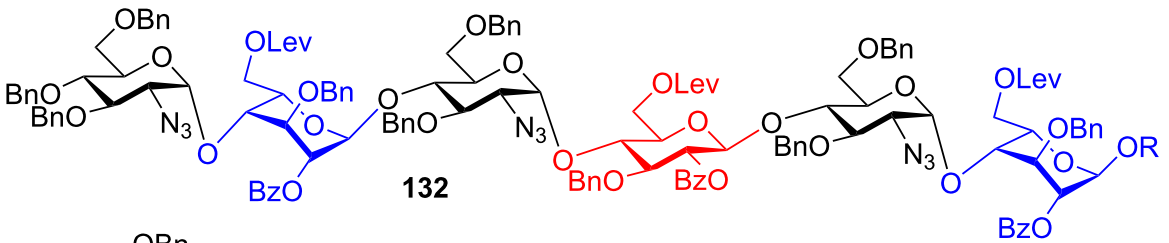

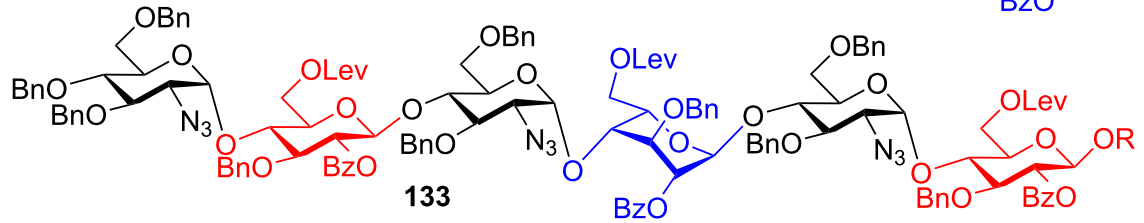

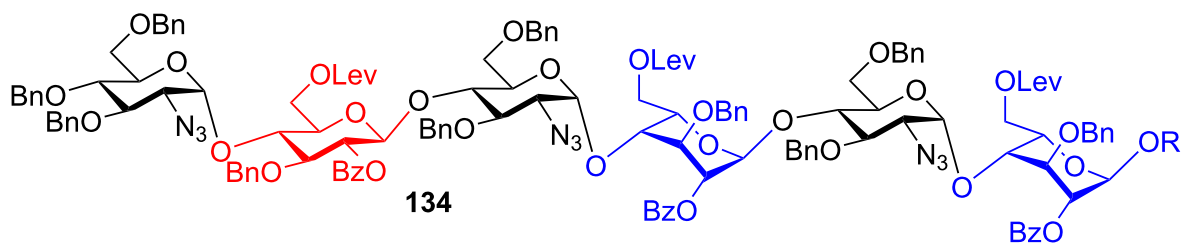

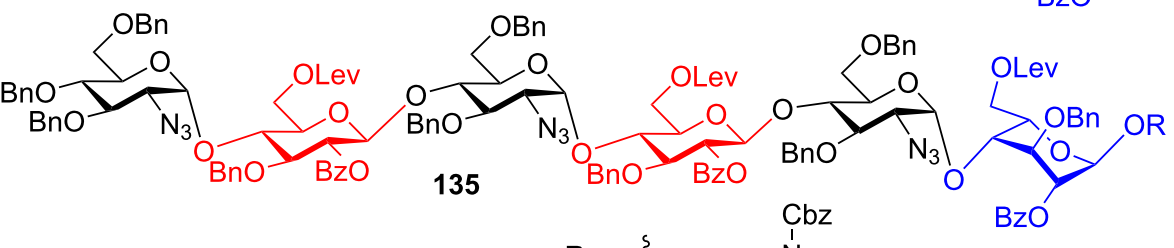<smiles>[R][14CH2][14CH2]CCCN(Cc1ccccc1)C(=O)OCc1ccccc1</smiles>

Figure 8: Preparation of a heparan sulfate oligosaccharides library.

fluorinated hydrazide $\mathbf{1 5 2}$ was added to the reaction mixture to selectively "catch" the desired tetrasaccharide $\mathbf{1 5 3}$, which was rapidly separated from non-fluorinated impurities by fluorous solid-phase extraction (F-SPE). Subsequent release of the compound from the fluorous tag and F-SPE yielded pure 153 in $61 \%$ overall yield from donor 83 . 


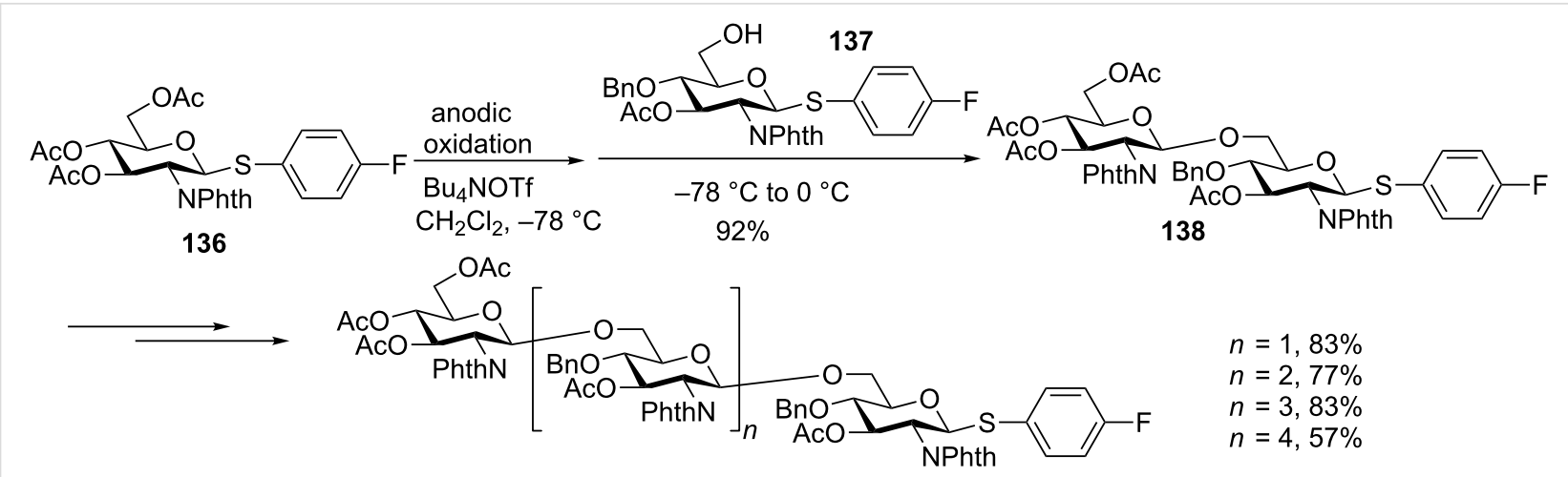

Scheme 20: Synthesis of oligo-glucosamines through electrochemical promoted preactivation-based thioglycoside glycosylation.
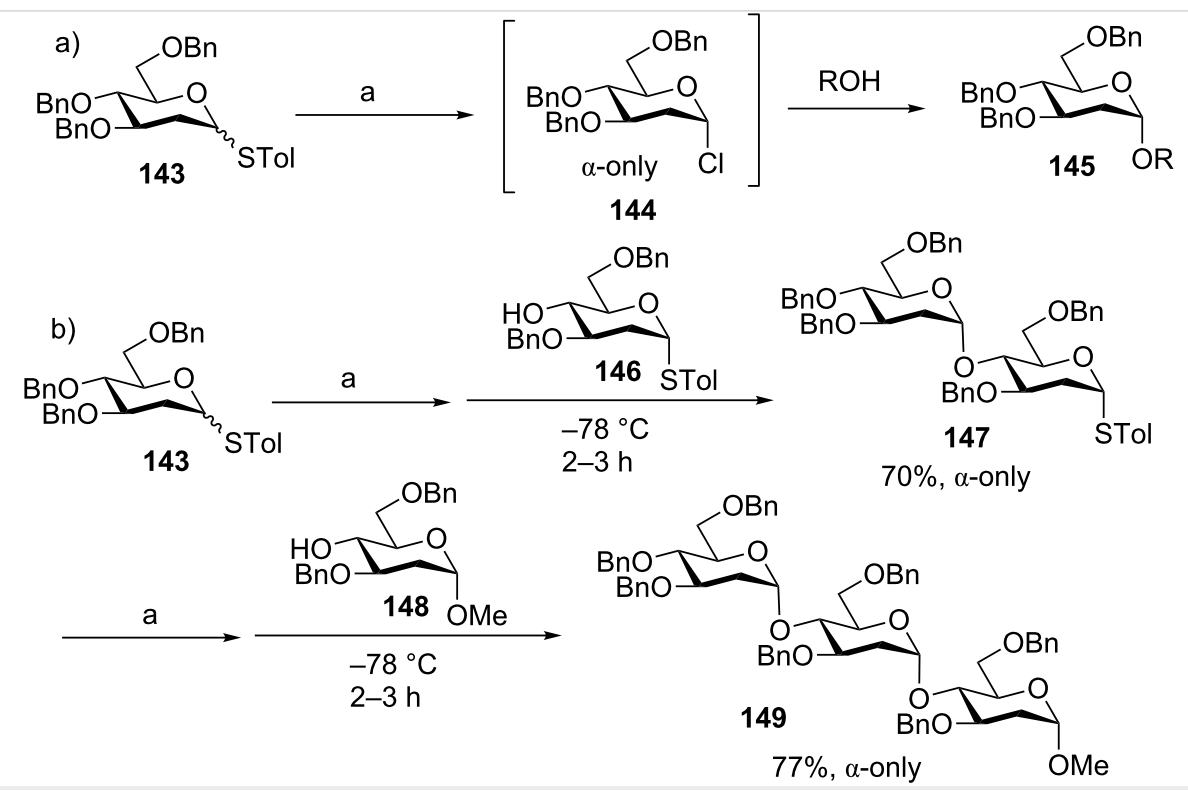

Scheme 21: Synthesis of 2-deoxyglucosides through preactivation. Reagents and conditions: a) AgOTf, $p$-TolSCl, $-78{ }^{\circ} \mathrm{C}$.

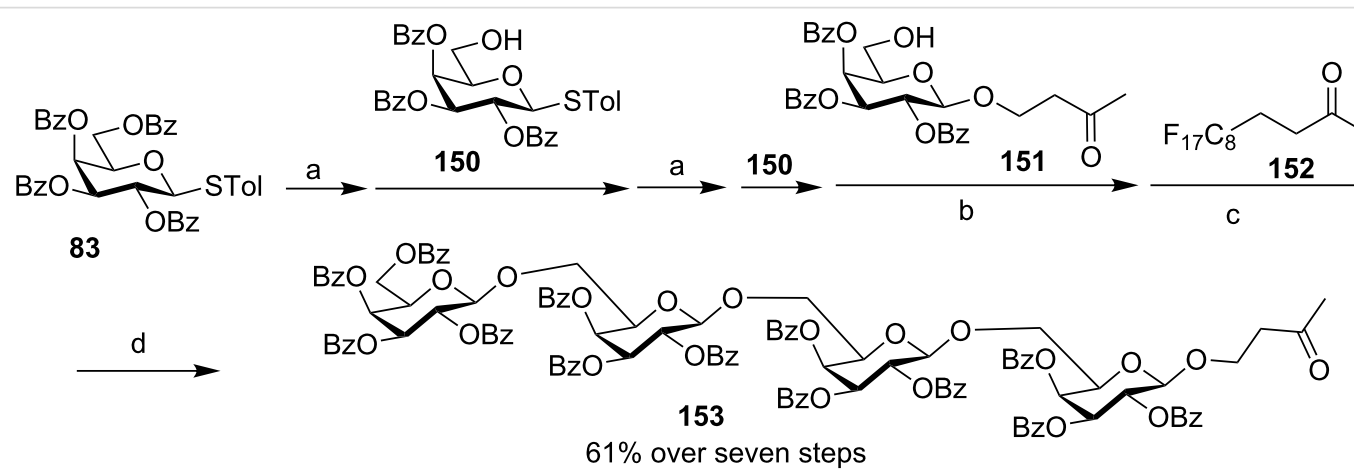

Scheme 22: Synthesis of tetrasaccharide 153. Reagents and conditions: (a) AgOTf, $p$-TolSCl, $\mathrm{CH}_{2} \mathrm{Cl}_{2},-78{ }^{\circ} \mathrm{C}$; then 150; (b) $\mathrm{AgOTf}, p$-TolSCl, $\mathrm{CH}_{2} \mathrm{Cl}_{2}, 150,-78^{\circ} \mathrm{C}$ to rt; (c) $\mathrm{CH}_{2} \mathrm{Cl}_{2} / \mathrm{MeOH}$, then F-SPE; (d) acetone/trifluoroacetic acid, then F-SPE.

One potential side reaction in using a thioglycosyl acceptor is the transfer of the thioaglycon of the acceptor to the activated donor presumably due to the high nucleophilicity of the aglycon compared with the hydroxy group of the acceptor (Scheme 23). Occasionally, the donor could be found regenerated upon addition of the acceptor following preactivation. This aglycon 

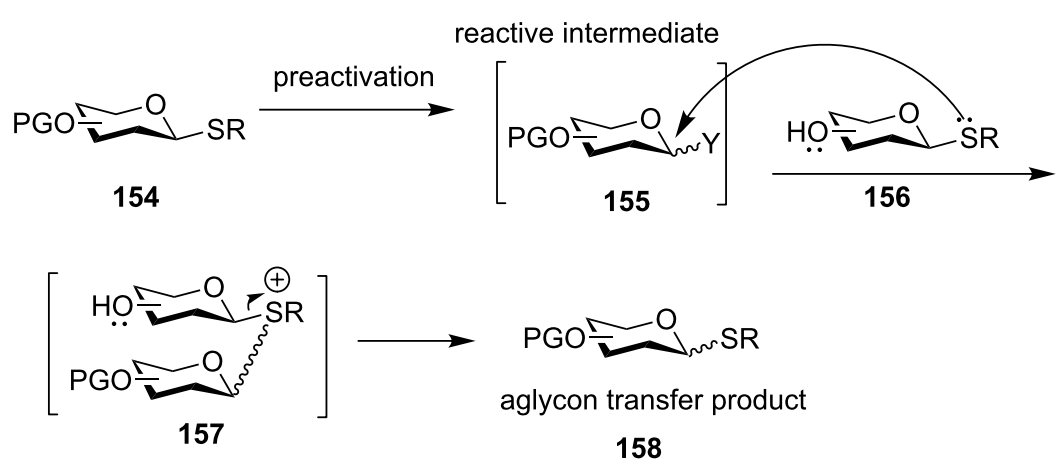

Scheme 23: Aglycon transfer from a thioglycosyl acceptor to an activated donor can occur during preactivation-based glycosylation reaction. This side reaction can be suppressed by tuning the reactivity of acceptor aglycon or manipulating the reaction temperature.

transfer phenomenon is not restricted to preactivation or thioglycosyl donors, as aglycon transfer products have been reported in premixed glycosylations with either glycosyl bromide or glycosyl trichloroacetimidate (Scheme 11b) [81-86]. The amounts of aglycon transfer products can be reduced by decreasing the nucleophilicity of the acceptor aglycon through steric effects [87] or tuning protective groups of acceptors $[84,86]$, in some cases by lowering the reaction temperature [85].

\section{Conclusion}

While conceptually simple, the temporal separation of donor activation and acceptor glycosylation in the preactivation protocol can enable chemoselective activation of the glycosyl donor without undesired acceptor activation. As a result, even an acceptor having higher anomeric reactivities than the glycosyl donor can be successfully glycosylated [18]. This protocol is found to be applicable to a wide range of glycosyl-donor types including thioglycosides, glycosyl sulfoxides, glycosyl hemiacetals, selenoglycosides, and 2-pyridyl glycosides. The newly formed oligosaccharide intermediate could be directly subjected to another round of preactivation and acceptor glycosylation without the need for additional synthetic operations to modify either protective groups or aglycon leaving groups. This can enable rapid glycan chain extension and improve overall synthetic efficiencies for glycan assembly.

Compared to the more traditional premixed method where both the glycosyl donor and the acceptor are present when the promoter is added, preactivation can generate reactive intermediates as the resting state allowing spectroscopic analysis such as low temperature NMR studies to better characterize the intermediate. This can help gaining a deeper insight into the reaction mechanism, which is critical for efforts to enhance the glycosylation yield.
The preactivation strategy is a powerful method for glycoassembly, which is evident from the successful synthesis of many complex oligosaccharides and glycoconjugates. However, glycosylation reactions are intrinsically sensitive to factors including protective groups on the glycan ring, reaction solvent, and additives present. As a result, further experimentation and analysis are needed to enable robust syntheses and achieve automation with comparable efficiencies of automated peptide and nucleic acid synthesis. With continuous development, the preactivation strategy will achieve wider applications in complex carbohydrate synthesis.

\section{Acknowledgements}

We are grateful for the financial support from National Science Foundation (CHE 1507226) and the National Institute of General Medical Sciences, NIH (R01GM072667).

\section{References}

1. Varki, A. Glycobiology 1993, 3, 97-130. doi:10.1093/glycob/3.2.97

2. Dwek, R. A. Chem. Rev. 1996, 96, 683-720. doi:10.1021/cr940283b

3. Bertozzi, C. R.; Kiessling, L. L. Science 2001, 291, 2357-2364. doi:10.1126/science.1059820

4. Zhu, X.; Schmidt, R. R. Angew. Chem., Int. Ed. 2009, 48, 1900-1934. doi:10.1002/anie.200802036

5. Huang, X.; Wang, Z. Strategies in Oligosaccharide Synthesis. In Comprehensive Glycoscience from Chemistry to Systems Biology; Kamerling, J. P., Ed.; Elsevier, 2007; Vol. 1, pp 379-413. doi:10.1016/B978-044451967-2/00011-8

6. Johnson, M.; Arles, C.; Boons, G.-J. Tetrahedron Lett. 1998, 39, 9801-9804. doi:10.1016/S0040-4039(98)02177-7

7. Roy, R.; Andersson, F. O.; Letellier, M. Tetrahedron Lett. 1992, 33, 6053-6056. doi:10.1016/S0040-4039(00)60004-7

8. Kim, K. S.; Kim, J. H.; Lee, Y. J.; Lee, Y. J.; Park, J. J. Am. Chem. Soc. 2001, 123, 8477-8481. doi:10.1021/ja015842s

9. Demchenko, A. V.; Pornsuriyasak, P.; De Meo, C.; Malysheva, N. N. Angew. Chem., Int. Ed. 2004, 43, 3069-3072. doi:10.1002/anie.200454047 
10. Kanie, O.; Ito, Y.; Ogawa, T. J. Am. Chem. Soc. 1994, 116, 12073-12074. doi:10.1021/ja00105a066

11. Zhang, Z.; Ollmann, I. R.; Ye, X.-S.; Wischnat, R.; Baasov, T.; Wong, C.-H. J. Am. Chem. Soc. 1999, 121, 734-753. doi:10.1021/ja982232s

12. Douglas, N. L.; Ley, S. V.; Lücking, U.; Warriner, S. L. J. Chem. Soc., Perkin Trans. 1 1998, 51-66. doi:10.1039/a705275h

13. Mootoo, D. R.; Konradsson, P.; Udodong, U.; Fraser-Reid, B. J. Am. Chem. Soc. 1988, 110, 5583-5584. doi:10.1021/ja00224a060

14. Huang, L.; Wang, Z.; Huang, X. Chem. Commun. 2004, 1960-1961. doi:10.1039/b405886k

15. Miura, T.; Hirose, Y.; Ohmae, M.; Inazu, T. Org. Lett. 2001, 3 , 3947-3950. doi:10.1021/ol0168380

16. Roychoudhury, R.; Pohl, N. L. B. Light Fluorous-Tag-Assisted Synthesis of Oligosaccharides. In Modern Synthetic Methods in Carbohydrate Chemistry: From Monosaccharides to Complex Glycoconjugates; Werz, D. B.; Vidal, S., Eds.; Wiley-VCH: Weinheim, 2013; pp 221-239. doi:10.1002/9783527658947.ch8

17. Plante, O. J.; Palmacci, E. R.; Seeberger, P. H. Science 2001, 291, 1523-1527. doi:10.1126/science.1057324

18. Huang, X.; Huang, L.; Wang, H.; Ye, X.-S. Angew. Chem., Int. Ed. 2004, 43, 5221-5224. doi:10.1002/anie.200460176

19. Codée, J. D. C.; van den Bos, L. J.; Litjens, R. E. J. N.; Overkleeft, H. S.; van Boeckel, C. A. A.; van Boom, J. H.; van der Marel, G. A. Tetrahedron 2004, 60, 1057-1064. doi:10.1016/j.tet.2003.11.084

20. Yamago, S.; Yamada, T.; Maruyama, T.; Yoshida, J.-i. Angew. Chem., Int. Ed. 2004, 43, 2145-2148. doi:10.1002/anie.200353552

21. Nguyen, H. M.; Poole, J. L.; Gin, D. Y. Angew. Chem., Int. Ed. 2001, 40, 414-417. doi:10.1002/1521-3773(20010119)40:2<414::AID-ANIE414>3.0.CO;26

22. Codée, J. D. C.; Litjens, R. E. J. N.; van den Bos, L. J.; Overkleeft, H. S.; van der Marel, G. A. Chem. Soc. Rev. 2005, 34, 769-782. doi:10.1039/b417138c

23. Wang, Y.; Ye, X.-S.; Zhang, L.-H. Org. Biomol. Chem. 2007, 5, 2189-2200. doi:10.1039/b704586g

24. Bouhall, S. K.; Sucheck, S. J. J. Carbohydr. Chem. 2014, 33, 347-367. doi:10.1080/07328303.2014.931964

25. Kahne, D.; Walker, S.; Cheng, Y.; Van Engen, D. J. Am. Chem. Soc. 1989, 111, 6881-6882. doi:10.1021/ja00199a081

26. Gargiulo, D.; Blizzard, T. A.; Nakanishi, K. Tetrahedron 1989, 45, 5423-5432. doi:10.1016/S0040-4020(01)89488-6

27. Yamago, S.; Yamada, T.; Hara, O.; Ito, H.; Mino, Y.; Yoshida, J.-i. Org. Lett. 2001, 3, 3867-3870. doi:10.1021/ol016713j

28. Yamago, S.; Yamada, T.; Ito, H.; Hara, O.; Mino, Y.; Yoshida, J.-i. Chem. - Eur. J. 2005, 11, 6159-6174. doi:10.1002/chem.200500126

29. Hanessian, S.; Lou, B. Chem. Rev. 2000, 100, 4443-4464. doi:10.1021/cr9903454

30. Xiong, D.-C.; Yang, A.-Q.; Yu, Y.; Ye, X.-S. Tetrahedron Lett. 2015, 56, 211-214. doi:10.1016/j.tetlet.2014.11.066

31. Hanessian, S. Preparative Carbohydrate Chemistry; Marcel Dekker Inc.: New York, 1997.

32. Toshima, K.; Tatsuta, K. Chem. Rev. 1993, 93, 1503-1531. doi:10.1021/cr00020a006

33. Sinaÿ, P. Pure Appl. Chem. 1991, 63, 519-528. doi:10.1351/pac199163040519

34. Danishefsky, S. J.; Bilodeau, M. T. Angew. Chem., Int. Ed. Engl. 1996, 35, 1380-1419. doi:10.1002/anie.199613801
35. Schmidt, R. R.; Kinzy, W. Adv. Carbohydr. Chem. Biochem. 1994, 50, 21-123. doi:10.1016/S0065-2318(08)60150-X

36. Garcia, B. A.; Poole, J. L.; Gin, D. Y. J. Am. Chem. Soc. 1997, 119, 7597-7598. doi:10.1021/ja971067y

37. Garcia, B. A.; Gin, D. Y. J. Am. Chem. Soc. 2000, 122, 4269-4279. doi:10.1021/ja993595a

38. Codée, J. D. C.; van den Bos, L. J.; Litjens, R. E. J. N.; Overkleeft, H. S.; van Boom, J. H.; van der Marel, G. A. Org. Lett. 2003, 5, 1947-1950. doi:10.1021/ol034528v

39. Dinkelaar, J.; Codée, J. D. C.; van den Bos, L. J.; Overkleeft, H. S.; van der Marel, G. A. J. Org. Chem. 2007, 72, 5737-5742. doi:10.1021/jo070704s

40. Codée, J. D. C.; Stubba, B.; Schiattarella, M.; Overkleeft, H. S.; van Boeckel, C. A. A.; van Boom, J. H.; van der Marel, G. A. J. Am. Chem. Soc. 2005, 127, 3767-3773. doi:10.1021/ja045613g

41. Garegg, P. J. Adv. Carbohydr. Chem. Biochem. 1997, 52, 179-205. doi:10.1016/S0065-2318(08)60091-8

42. Koeller, K. M.; Wong, C.-H. Chem. Rev. 2000, 100, 4465-4493. doi:10.1021/cr990297n and references cited therein

43. Geurtsen, R.; Holmes, D. S.; Boons, G.-J. J. Org. Chem. 1997, 62, 8145-8154. doi:10.1021/jo971233k

44. Li, X.; Huang, L.; Hu, X.; Huang, X. Org. Biomol. Chem. 2009, 7, 117-127. doi:10.1039/B813048E

45. Jennum, C. A.; Fenger, T. H.; Bruun, L. M.; Madsen, R. Eur. J. Org. Chem. 2014, 3232-3241. doi:10.1002/ejoc.201400164

46. Hsu, Y.; Lu, X.-A.; Zulueta, M. M. L.; Tsai, C.-M.; Lin, K.-I.; Hung, S.-C.; Wong, C.-H. J. Am. Chem. Soc. 2012, 134, 4549-4552. doi:10.1021/ja300284x

47. Burkhart, F.; Zhang, Z.; Wacowich-Sgarbi, S.; Wong, C.-H Angew. Chem., Int. Ed. 2001, 40, 1274-1277. doi:10.1002/1521-3773(20010401)40:7<1274::AID-ANIE1274>3.0.CO; 2-W

48. Polat, T.; Wong, C.-H. J. Am. Chem. Soc. 2007, 129, 12795-12800. doi:10.1021/ja073098r

49. Crich, D.; Smith, M. J. Am. Chem. Soc. 2001, 123, 9015-9020. doi:10.1021/ja0111481

50. Crich, D.; Smith, M. Org. Lett. 2000, 2, 4067-4069. doi:10.1021/ol006715o

51. Codée, J. D. C.; Litjens, R. E. J. N.; den Heeten, R.; Overkleeft, H. S.; van Boom, J. H.; van der Marel, G. A. Org. Lett. 2003, 5, 1519-1522. doi:10.1021/ol034312t

52. Peng, P.; Ye, X.-S. Org. Biomol. Chem. 2011, 9, 616-622. doi:10.1039/C0OB00380H

53. Wang, C.; Wang, H.; Huang, X.; Zhang, L.-H.; Ye, X.-S. Synlett 2006, 2846-2850. doi:10.1055/s-2006-950247

54. Crich, D.; Li, W.; Li, H. J. Am. Chem. Soc. 2004, 126, 15081-15086. doi:10.1021/ja0471931

55. Son, S.-H.; Tano, C.; Furuike, T.; Sakairi, N. Carbohydr. Res. 2009, 344, 285-290. doi:10.1016/j.carres.2008.11.008

56. Crich, D.; Sun, S. J. Am. Chem. Soc. 1997, 119, 11217-11223. doi:10.1021/ja971239r

57. Zeng, Y.; Wang, Z.; Whitfield, D.; Huang, X. J. Org. Chem. 2008, 73, 7952-7962. doi:10.1021/jo801462r

58. Suga, S.; Suzuki, S.; Yamamoto, A.; Yoshida, J.-i. J. Am. Chem. Soc. 2000, 122, 10244-10245. doi:10.1021/ja002123p

59. Nokami, T.; Shibuya, A.; Tsuyama, H.; Suga, S.; Bowers, A. A.; Crich, D.; Yoshida, J.-i. J. Am. Chem. Soc. 2007, 129, 10922-10928. doi:10.1021/ja072440x 
60. Wang, Z.; Zhou, L.; El-Boubbou, K.; Ye, X.-S.; Huang, X. J. Org. Chem. 2007, 72, 6409-6420. doi:10.1021/j0070585g

61. Werz, D. B.; Castagner, B.; Seeberger, P. H. J. Am. Chem. Soc. 2007, 129, 2770-2771. doi:10.1021/ja069218x

62. Wu, Y.; Xiong, D.-C.; Chen, S.-C.; Wang, Y.-S.; Ye, X.-S. Nat. Commun. 2017, 8, No. 14851. doi:10.1038/ncomms14851

63. Miermont, A.; Zeng, Y.; Jing, Y.; Ye, X.-s.; Huang, X. J. Org. Chem. 2007, 72, 8958-8961. doi:10.1021/jo701694k

64. Gao, J.; Guo, Z. J. Org. Chem. 2013, 78, 12717-12725. doi:10.1021/jo4021979

65. Sun, B.; Yang, B.; Huang, X. Sci. China: Chem. 2012, 55, 31-35. doi:10.1007/s11426-011-4449-X

66. Yin, Z.; Dulaney, S.; McKay, C. S.; Baniel, C.; Kaczanowska, K.; Ramadan, S.; Finn, M. G.; Huang, X. ChemBioChem 2016, 17 , 174-180. doi:10.1002/cbic.201500499

67. Gao, J.; Guo, Z. Org. Lett. 2016, 18, 5552-5555. doi:10.1021/acs.orglett.6b02796

68. Liao, G.; Zhou, Z.; Burgula, S.; Liao, J.; Yuan, C.; Wu, Q.; Guo, Z. Bioconjugate Chem. 2015, 26, 466-476. doi:10.1021/bc500575a

69. Liao, G.; Burgula, S.; Zhou, Z.; Guo, Z. Eur. J. Org. Chem. 2015, 2942-2951. doi:10.1002/ejoc.201500229

70. Huang, L.; Wang, Z.; Li, X.; Ye, X.-s.; Huang, X. Carbohydr. Res. 2006, 341, 1669-1679. doi:10.1016/j.carres.2006.01.007

71. Sun, B.; Srinivasan, B.; Huang, X. Chem. - Eur. J. 2008, 14, 7072-7081. doi:10.1002/chem.200800757

72. Huang, L.; Huang, X. Chem. - Eur. J. 2007, 13, 529-540. doi:10.1002/chem.200601090

73. Lu, X.; Kamat, M. N.; Huang, L.; Huang, X. J. Org. Chem. 2009, 74, 7608-7617. doi:10.1021/jo9016925

74. Wang, Z.; Xu, Y.; Yang, B.; Tiruchinapally, G.; Sun, B.; Liu, R.; Dulaney, S.; Liu, J.; Huang, X. Chem. - Eur. J. 2010, 16, 8365-8375. doi:10.1002/chem.201000987

75. Tiruchinapally, G.; Yin, Z.; El-Dakdouki, M.; Wang, Z.; Huang, X. Chem. - Eur. J. 2011, 17, 10106-10112. doi:10.1002/chem.201101108

76. Sun, B.; Jiang, H. Tetrahedron Lett. 2011, 52, 6035-6038. doi:10.1016/j.tetlet.2011.09.022

77. Wang, C.-C.; Lee, J.-C.; Luo, S.-Y.; Kulkarni, S. S.; Huang, Y.-W.; Lee, C.-C.; Chang, K.-L.; Hung, S.-C. Nature 2007, 446, 896-899. doi:10.1038/nature05730

78. Nokami, T.; Hayashi, R.; Saigusa, Y.; Shimizu, A.; Liu, C.-Y.; Mong, K.-K. T.; Yoshida, J.-i. Org. Lett. 2013, 15, 4520-4523. doi:10.1021/ol402034g

79. Verma, V. P.; Wang, C.-C. Chem. - Eur. J. 2013, 19, 846-851. doi:10.1002/chem.201203418

80. Yang, B.; Jing, Y.; Huang, X. Eur. J. Org. Chem. 2010, 1290-1298. doi:10.1002/ejoc.200901155

81. Auzanneau, F.-I.; Bundle, D. R. Carbohydr. Res. 1991, 212, 13-24. doi:10.1016/0008-6215(91)84041-C

82. Leigh, D. A.; Smart, J. P.; Truscello, A. M. Carbohydr. Res. 1995, 276, 417-424. doi:10.1016/0008-6215(95)00182-S

83. Belot, F.; Jacquinet, J.-C. Carbohydr. Res. 1996, 290, 79-86. doi:10.1016/0008-6215(96)00116-4

84. Zhu, T.; Boons, G.-J. Carbohydr. Res. 2000, 329, 709-715. doi:10.1016/S0008-6215(00)00252-4

85. Yu, H.; Yu, B.; Wu, X.; Hui, Y.; Han, X. J. Chem. Soc., Perkin Trans. 1 2000, 1445-1453. doi:10.1039/a909218h

86. Li, Z.; Gildersleeve, J. C. Tetrahedron Lett. 2007, 48, 559-562. doi:10.1016/j.tetlet.2006.11.126

87. Li, Z.; Gildersleeve, J. C. J. Am. Chem. Soc. 2006, 128, 11612-11619. doi:10.1021/ja063247q

\section{License and Terms}

This is an Open Access article under the terms of the Creative Commons Attribution License

(http://creativecommons.org/licenses/by/4.0), which permits unrestricted use, distribution, and reproduction in any medium, provided the original work is properly cited.

The license is subject to the Beilstein Journal of Organic Chemistry terms and conditions:

(http://www.beilstein-journals.org/bjoc)

The definitive version of this article is the electronic one which can be found at:

doi:10.3762/bjoc. 13.207 